\title{
The 2017 Mw 5.5 Pohang earthquake, South Korea, and poroelastic stress changes associated with fluid injection
}

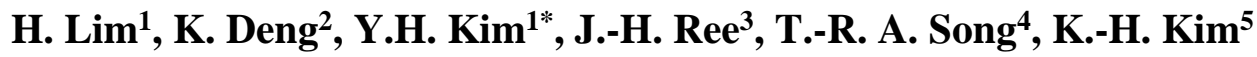

${ }^{1}$ School of Earth and Environmental Sciences, Seoul National University, Seoul 08826, Republic of Korea

${ }^{2}$ College of Geophysics, Chengdu University of Technology, Sichuan 610059, China

${ }^{3}$ Department of Earth and Environmental Sciences, Korea University, Seoul 02841, Republic of Korea

${ }^{4}$ Department of Earth Sciences, University College London, Kathleen-Lonsdale Building, Gower Street, London WC1E 6BT, United Kingdom

${ }^{5}$ Department of Geological Science, Pusan National University, Busan 46241, Republic of Korea

Corresponding author: YoungHee Kim (younghkim@snu.ac.kr)

\section{Key Points:}

- We calculate poroelastic stress changes associated with fluid injection to understand the nature of the 2017 Pohang earthquake.

- Our slow diffusion model with a low hydraulic diffusivity parameter explains the delayed occurrence of the 2017 Pohang earthquake. 
The 2017 Mw 5.5 Pohang earthquake in South Korea, the first reported and largest-magnitude induced earthquake, occurred near the enhanced geothermal power plant in Pohang on 15 November 2017. We compute the spatiotemporal changes in poroelastic stresses perturbed by injected fluid under various conditions to better understand the occurrences of the Pohang earthquake and the small-magnitude earthquakes preceding it. Space-time variation of the earthquakes that occurred before the Pohang earthquake correlates significantly with fluid injection history between January 2016 and September 2017. We attribute the timing in earthquake occurrence to slow fluid diffusion, making hydraulic diffusivity of bedrock the critical model parameter for representing this slow process. In this context, the delay between the injection and the Pohang earthquake requires diffusivity estimates within a range of $1 \times 10^{-4}-5 \times$ $10^{-4} \mathrm{~m}^{2} / \mathrm{s}$ for damaged granodiorite at $4-5 \mathrm{~km}$, corresponding to the depth range between the well

34 and the focal depth. According to these estimates, the pore pressure, and thus the Coulomb

35 failure stress changes, are further enhanced by each injection with minimum stress dissipation. We find fluid injection can result in a change of the Coulomb stress of up to 0.4-1.1 bar,

37 exceeding those associated with the $2016 \mathrm{Mw} 5.5$ Gyeongju earthquake by two orders of magnitude. 


\section{Introduction}

The first enhanced geothermal system (EGS) project was initiated in late 2010 in Pohang, South Korea (Park et al., 2017), where the highest geothermal gradient and heat flow are observed (Figure 1; Kim and Lee, 2007; Lee et al., 2010). Injection wells (denoted by PX-1 and PX-2) were drilled to depths of 4,362 and 4,341 m, respectively, and the first high-pressure hydraulic stimulation began on 29 January 2016 (Park et al., 2017; Hofmann et al., 2019). Before the last fluid injection on 18 September 2017, an earthquake occurred on 15 April 2017 at or near the EGS site with a moment magnitude, Mw, of 3.2 (Kim et al., 2018; Korean Government Commission, 2019 (KGC, 2019, hereafter); Woo et al., 2019). Seven months later on 15 November 2017, the Mw 5.5 earthquake occurred in close proximity to the well locations (Grigoli et al., 2018; Kim et al., 2018; Ellsworth et al., 2019; KGC, 2019; Woo et al., 2019), and it was the second-largest and the most destructive event on record since seismic instrumental monitoring began in South Korea in 1905 (Lee et al., 2003). Prior to the injection, a mud loss event to the amount of $650 \mathrm{~m}^{3}$ occurred during drilling in October-November 2015 (KGC, 2019). KGC (2019) identified two clusters of seismicity associated with fluid injection at PX-1 and PX-2, and further suggested that the Pohang earthquake intiated in an area that was perturbed by the injection at PX-2. Because the focal depth is estimated to be relatively shallow, at about 4-5 km (Grigoli et al., 2018; Kim et al., 2018; KGC, 2019; Woo et al., 2019), synthetic aperture radar interferometry (InSAR) constrains the static slip model (Song and Lee, 2019), showing a major slip northeast of the hypocenter.

The space-time variation of seismicity prior to the Mw 5.5 earthquake is well correlated with the history of stimulation activities involving fluid injection and flowback (Kim et al., 2018). The proximity of the focal depth to the well tip and the temporal correlation between 
seismicity and hydraulic stimulation support the idea that geothermal plant activities may have caused the Mw 5.5 Pohang earthquake (Grigoli et al., 2018; Kim et al., 2018; Ellsworth et al., 2019; KGC, 2019; Woo et al., 2019), making it the largest induced earthquake on record at an EGS site. Herein, the term 'induced' is used to include earthquakes triggered by anthropogenic causes that release tectonic stress, as well as earthquakes that release the stresses created by industrial activities (Doglioni, 2018; Ellsworth, 2013). In regions where the crust is critically stressed (e.g., Hong et al., 2018), small changes in stress can trigger fault slip, causing earthquakes (Reasenberg and Simpson, 1992; Stein, 1999).

It remains unclear how the injected fluid from the Pohang EGS activities affected the stress state at depth and induced the earthquake that occurred about 2 months after the last stimulation activity, on 18 September 2017 (Figure 2; Kim et al., 2018). KGC (2019) conducted a comprehensive study to investigate the cause of the Pohang earthquake, utilizing datasets from seismology, hydrogeology, geomechanics/structural geology, and geophysical exploration. A condensed version of this work by KGC (2019) is presented in Ellsworth et al. (2019). In particular, KGC (2019) provided locations for earthquakes that occurred near the EGS site during the period between the start of the EGS activities and the mainshock, which we refer to as 'previous earthquakes'. KGC (2019) also provided hydraulic models for limited cases using the hydraulic diffusivities $(D)$ of the fault core and fault damage zone and suggested that an increases in fluid pressure of $\sim 0.7$ bar was probably present when the Pohang earthquake occurred on 15 November 2017.

In this study, we perform poroelastic modeling to calculate the injection-related pore pressure and stress perturbations within the framework of linear poroelasticity (e.g., Biot, 1941), but consider a wide range of $D$ in the modeling to assess uncertainties in the medium properties. 
While both hydraulic and poroelastic analyses predict pore pressure changes, the poroelastic modeling can selfconsistently predict changes in elastic stress due to fluid injection. Under low diffusivity, the elastic stress change could be a dominant triggering mechanism (e.g., Deng et al., 2016). Furthermore, although high $D$ is observed within a localized zone $(<\sim 100 \mathrm{~m})$ near the well during high-pressure stimulation (Yoo, 2018), if the fault associated with the mainshock is located beyond the nearwell fractured zone (e.g., Ellsworth et al., 2019; KGC, 2019), the hydraulic property of bedrock at the basement, likely to be low (e.g., Mizoguchi et al., 2008; Morrow et al., 1994), will play a critical role in affecting the pore pressure change due to the injection.

\section{Considering the history of stimulation activities and geological setting at the Pohang}

EGS site (Kim et al., 2018; Lee et al., 2015), we investigate the dependence of stress change with respect to $D$, and compare the relocated seismicity with the spatiotemporal evolution of Coulomb stress change. In this study, we determine the locations of the Mw 5.5 Pohang earthquake and 311 smaller earthquakes at or near the EGS site, including 11 previous earthquakes and 302 aftershocks that occurred between December 2016 and February 2018. We take a probabilistic approach in determining these earthquake locations and tightly link the stress change to the earthquake's location.

\section{Poroelastic modeling}

\subsection{Poroelastic constitutive equations}

Biot's poroelastic equation (1941) describes the equilibrium condition for the solid matrix and pore fluid pressure in a poroelastic medium that shows fluid-matrix coupling. The medium is 
108

109

110

111 and

112

113

114

115

116

117

118

119

120

121

122

assumed to be isotropic and fluid-saturated. The governing equations are given as follows

(Detournay and Cheng, 1993; Wang and Kümpel, 2003):

$$
\mathrm{G} \nabla^{2} \mathbf{u}+\frac{2 \mathrm{G}}{1-2 v} \nabla \epsilon-\alpha \nabla \mathrm{p}=\mathbf{f}(\mathbf{x}, \mathrm{t})
$$

$$
\mathrm{M}^{-1} \frac{\partial \mathrm{p}}{\partial \mathrm{t}}+\alpha \frac{\partial \epsilon}{\partial \mathrm{t}}-\nabla \cdot\left(\frac{\kappa}{\eta} \nabla \mathrm{p}\right)=\mathrm{Q}(\mathrm{x}, \mathrm{t})
$$

where $\mathbf{u}$ is the displacement vector, $\epsilon$ is the volumetric strain (i.e., $\nabla \cdot \mathbf{u}$ ), $p$ is the pore pressure, $\kappa$ is the matrix permeability, $\eta$ is the dynamic viscosity of the fluid, and $\mathbf{f}$ is the body force per unit volume. $\mathrm{Q}(\mathrm{x}, \mathrm{t})$ is described by $\mathrm{q}(\mathrm{t}) \delta\left(\mathrm{x}-\mathbf{x}_{\mathbf{s}}\right)$ for a single point source, where $\mathrm{q}(\mathrm{t})$ is the injection rate, $\mathbf{x}_{\mathrm{s}}$ is the location of the injection well, and $\delta(\cdot)$ is the Dirac delta function. The poroelastic medium is characterized by the independent parameters $G, v, M, \alpha$, and $D$, where $G$ is the shear modulus, $v$ is Poisson's ratio under drained conditions, $M$ is the Biot modulus (compressibility introduced by Biot (1941)), and $\alpha$ is a dimensionless coefficient of effective stress (Biot, 1941). The permeability $\kappa$ is related to $D$ by

$$
\frac{\kappa}{\eta}=\frac{9}{2} \frac{\left(1-v_{\mathrm{u}}\right)\left(v_{\mathrm{u}}-v\right) \mathrm{D}}{(1-v)\left(1+v_{\mathrm{u}}\right)^{2} \mathrm{~GB}^{2}}
$$

where $B$ is Skempton's coefficient. $\mathrm{M}^{-1}$ is expressed as

$$
\mathrm{M}^{-1}=\frac{9}{2} \frac{\left(1-2 v_{\mathrm{u}}\right)\left(v_{\mathrm{u}}-v\right)}{(1-2 v)\left(1+v_{\mathrm{u}}\right)^{2} \mathrm{~GB}^{2}}
$$

where $v_{\mathrm{u}}=[3 v+\alpha \mathrm{B}(1-2 v)] /[3-\alpha \mathrm{B}(1-2 v)]$ is Poisson's ratio under the undrained condition.

For calculating the poroelastic stress and pore pressure changes with given injection rate, 
we use the poel softwafe (https://www.gfz-potsdam.de/en/section/physics-of-earthquakes-andvolcanoes/data-products-services/downloads-software; last accessed on 21 June 2017), which is based on an extension of the Thomson-Haskell propagator method (Wang and Kümpel, 2003). We consider the real-time injection histories at PX-1 and PX-2 (Figures 2b and c) and calculate stress and pore pressure changes in cylindrical coordinates system, where the axis of symmetry is defined perpendicular to the fault. We apply no free-surface condition in the calculation as any effect due to a free surface is minimal when the point of interest is close to the wells and away from the free surface (Wang and Kümpel, 2003). The stress tensors from PX-1 and PX-2 are rotated to a specific fault orientation, and the total stress perturbation is obtained by the principle of superposition, taking advantage of the linearity of poroelastic theory.

\subsection{Poroelastic parameters}

All poroelastic parameters used in the modeling except for $D(G, B, v, \alpha$, and $\eta)$ are summarized in Table 1. Their ranges represent granite or crustal rock in a confining pressure and temperure at a depth of $4 \mathrm{~km}$ (Table 1). The values of $G, B, v, \alpha$, and $\eta$ are fixed because their ranges are narrow relatively to $D$. We also append rationale for selecting the values in Table 1 .

$D$ represents the ratio between the rock's ability to store and transport fluids in the poroelastic medium. For fixed poroelastic parameters $(G, B, v, \alpha$, and $\eta)$ other than $D$ itself in Table 1, $D$ can be converted to $\kappa$ and vice versa using Equation (3). Figure S1 shows the linear relationship between $D$ and $\kappa$. However, selection of values of $D$ for modeling is not trivial. For example, $D$ of the fractured granite of the Nojima fault zone in Japan $\left(8 \mathrm{~m}^{2} / \mathrm{s} ; \kappa=10^{-14} \mathrm{~m}^{2}\right)$ is much higher than that of the fault-wall rocks $\left(8 \times 10^{-6} \mathrm{~m}^{2} / \mathrm{s} ; \kappa=10^{-20} \mathrm{~m}^{2}\right)$, while the fault gouge 
148

149

150

151

152

153

154

155

156

157

158

159

160

161

162

163

164

165

166

167

168

169

can have very low $D\left(8 \times 10^{-6} \mathrm{~m}^{2} / \mathrm{s} ; \kappa=10^{-20} \mathrm{~m}^{2}\right)$ at the effective confining pressure $\left(P_{\mathrm{e}}\right)$ of 0.9 kbar (Mizoguchi et al., 2008). For comparison, the measured $\kappa$ of the intact granodiorite gneiss samples from the Kola well in Russia is $4-7 \times 10^{-21} \mathrm{~m}^{2}\left(D=3-6 \times 10^{-6} \mathrm{~m}^{2} / \mathrm{s}\right)$ at $P_{\mathrm{e}}=1 \mathrm{kbar}$ (Morrow et al., 1994).

For the Pohang earthquake, Ellsworth et al. (2019) and KGC (2019) used $D=10^{-2} \mathrm{~m}^{2} / \mathrm{s}$ for bedrock, $10^{-6} \mathrm{~m}^{2} / \mathrm{s}$ for fault core and $10^{-1} \mathrm{~m}^{2} / \mathrm{s}$ for the fault damage zone in their pore pressure diffusion modeling. Yoo (2018) calculated the stress-dependent permeability, which reaches $10^{-}$ ${ }^{15} \mathrm{~m}^{2}$ at a radial distance of $15 \mathrm{~m}\left(1 \mathrm{~m}^{2} / \mathrm{s}\right)$ from PX-2, using the densely sampled wellhead pressure and injection rate data during 29-30 January 2016. Also, calculated permeability is 2-5 $\times 10^{-14} \mathrm{~m}^{2}$ at $22.5 \mathrm{~m}\left(16-40 \mathrm{~m}^{2} / \mathrm{s}\right)$ from PX-1 for 15-16 December 2016 (Yoo, 2018). This value of $D$ specifically represents the fluid diffusion properties in a spatially localized region near the well $(<\sim 100 \mathrm{~m})$, which must have been transient for 2-3 days. We thus set this value of $D$ as the upper bound in our modeling. Considering previously determined estimates of $D$ for the Pohang EGS and other fault-zones, we explore wide ranges of this variable $\left(10^{-7}-10^{3} \mathrm{~m}^{2} / \mathrm{s}\right)$ for the bedrock $\left(D_{\text {bed }}\right)$ and fault damage zone $\left(D_{\mathrm{dmz}}\right)$ in our modeling and compute stress changes with approximately uniform intervals (e.g., $D=1 \times 10^{-7}, 2 \times 10^{-7}, 5 \times 10^{-7}, 1 \times 10^{-6} \mathrm{~m}^{2} / \mathrm{s}$, and so on). Although we do not search for a range of $D$ for the fault core (i.e., fault gouge), $D_{\text {core, }}$ we discuss the effects of an impermeable fault gouge on the changes in the stresses and pore pressure in

\section{Section 4.5.}


170 from the vertical PX-2; at their bottoms, they are $616 \mathrm{~m}$ apart laterally (Hofmann et al., 2019).

171 The openhole sections, along which fluid is injected into or extracted from rock, of PX-1 and

172 PX-2 are at 4,049-4,362 $\mathrm{m}$ and 4,208-4,348 $\mathrm{m}$ depth, respectively (Hofmann et al., 2019). The

173 locations of vertical PX-2 and the surface-projected location of the openhole section of tilted PX-

1741 are shown in Figure 3. Geometries of the openhole sections in fault-plane and fault-normal

175 views are presented in Figure 4. Injections are simplified as point sources at the mid-point of the

176 relevant openhole section (Figure 4, white circle).

Fluid injection and flowback records from between 29 January 2016 and 18 September 2017 are presented in Figure 2 (Kim et al., 2018; KGC, 2019). The injection phases are grouped into five events dated to January-February 2016 (hereafter, JF16), December 2016 (D16), March-April 2017 (MA17), August 2017 (A17) and September 2017 (S17). The injection events JF16, D16, MA17, A17, and S17 were performed at PX-2, PX-1, PX-2, PX-1, and PX-2, respectively (Figure 2; Kim et al., 2018; KGC, 2019).

A failure occurs on a fault when the shear stress $(\tau)$ exceeds the maximum frictional strength that is determined by a frictional coefficient $(\mu)$, normal stress $\left(\sigma_{\mathrm{n}}\right)$, and $p . \tau$ is resolved on the fault surface geometry, defined by the strike, dip, and rake, from the known stress field, whereas $\sigma_{\mathrm{n}}$ is defined only by the strike and dip. $p$ is independent of fault geometry. $\tau$ is positive in the rake direction, and $\sigma_{\mathrm{n}}$ is positive for tension. The Coulomb failure stress $(C F S)$ is defined as CFS $=\tau+\mu\left(\sigma_{n}+p\right)$ (e.g., King et al., 1994; Stein, 1999). We consider that failure on a fault is promoted (or inhibited) due to changes in the CFS, or $\triangle C F S$, which is defined as 


$$
\Delta \mathrm{CFS}=\Delta \tau+\mu\left(\Delta \sigma_{\mathrm{n}}+\Delta \mathrm{p}\right) .
$$

193 The fault is brought closer to failure when $\triangle C F S$ is positive, and vice versa. The increases in $\Delta \tau$,

$194 \Delta p$, and $\Delta \sigma_{\mathrm{n}}$ increase the likelihood that the fault will slip toward the assumed slip direction. For 195 most rocks, the frictional coefficient $(\mu)$ ranges between 0.6 and 0.85 (Byerlee, 1978) (Table 1).

196 In this study, we use $\mu$ of 0.6 (Table 1), which is close to the coefficient of 0.53 in the

197 granodiorite sample retrieved from the well PX-2 at a depth of $4.2 \mathrm{~km}$ (Kwon et al., 2018).

198 To compute $\triangle C F S$, the stress tensor obtained from Equations (1) and (2) is projected onto the

199 fault plane to obtain $\Delta \sigma_{\mathrm{n}}$ and $\Delta \tau$ along the slip direction. The fault defined by the strike, dip and 200 rake is referred to as a 'receiver fault' (e.g., Woessner et al., 2012), which can be of fixed 201 geometry or arbitrarily oriented along the fault plane that is most susceptible to failure (the 202 'optimal fault orientation') in the modeling domain. We use the fault geometry constrained by 203 the distribution of the Pohang earthquake and previous earthquakes before the mainshock (strike 204 of $214^{\circ}$ and dip of $43^{\circ}$; Woo et al., 2019) as our receiver fault. Rake is chosen as $128^{\circ}$ from the 205 mainshock focal mechanism (KGC, 2019; Woo et al., 2019).

\section{Earthquake location}

The Pohang earthquake was recorded by a permanent seismic network in South Korea, two strong-motion sensors at the EGS site (Grigoli et al., 2018), and a temporary array (Kim et al.,

210 2018), consisting of a total of 68 seismometers near/at the EGS (Figures 1 and S2). In the

211 aftermath of the Pohang earthquake, several temporary seismic arrays were deployed close to the 212 site to monitor aftershocks (Figures 1 and S2). Since earthquake locations are critical for 
213 evaluating poroelastic stress changes, we relocate the Pohang earthquake, its aftershocks, and

214 previous earthquakes using available network data. We then assess our estimates by comparing

215 with estimates from previous studies based on different location methods and datasets. See

216 Appendix A for details of how to obtain the obtaining probability density functions ( $p d f \mathrm{~s}$ ) of the

217 hypocenters. See Table S1 for our hypocenter locations and uncertainties.

219 Figures $3 \mathrm{a}$ and $\mathrm{b}$ show the epicentral $p d f \mathrm{~s}$ (i.e., marginal $p d f \mathrm{~s}$ ) of the earthquakes. In particular, 220 the median of the epicentral $p d f$ for the Pohang earthquake is indicated as a star with an iso221 contour line (95\% of the $p d f \mathrm{~s})$. The $95 \%$ iso-contour of the Pohang earthquake has a radius of, at 222 most, $1 \mathrm{~km}$ that encompasses the locations of both wells. Furthermore, the iso-contour 223 encompasses the previous estimate of its hypocenter (Ellsworth et al., 2019; KGC, 2019; Woo et 224 al., 2019). The observed difference in epicenters between the previous estimate and ours (median 225 of $p d f$ ) is $\sim 200-1000 \mathrm{~m}$, which is inevitable considering that different datasets have been utilized 226 in relocation.

$228 \sim 4$ to $6 \mathrm{~km}$ (Figure 3c). The previous estimates of $4.27 \mathrm{~km}(\mathrm{KGC}, 2019)$ and $6.2 \mathrm{~km}$ (Hong et al., 229 2018) are within our determined range, which corresponds to the depth range of granodiorite 230 basement (Lee et al., 2015). 
December 2016, Mw 2.3 on 29 December 2016, and Mw 3.2 on 15 April 2017; Figure 2a; magnitude information taken from $\mathrm{KGC}, 2019)$ is indicated as a circle with an iso-contour line (95\% of the $p d f$; Figure 3a). Among the detected earthquakes by Kim et al. (2018) and KGC (2019; Figure 2a), these three events each have a value of Mw exceeding 2.1. The locations of these previous earthquakes involve large uncertainty and are far from the well positions (Figure 3a) since data from the networks PH, K18, G18 and KG (temp) are unavailable (Figure 1). The depths of the $\mathrm{Mw} 3.2, \mathrm{Mw} 2.2$ and $\mathrm{Mw} 2.3$ earthquakes are $5.9 \pm 5.5 \mathrm{~km}, 2.3 \pm 2.3 \mathrm{~km}$ and $1.5 \pm$ $0.8 \mathrm{~km}$, respectively.

The hypocenters of seven foreshocks with a magnitude less than 2.2 (which occurred from 14 November 2017, 20:04 to 15 November 2017, 05:23) are relatively well determined compared to those of previous earthquakes because of the stations K18 (Figures 1 and 3a; Table S1). Most of the foreshocks (six out of seven) are located near the wells and they are confined to a depth range of 4.0-4.9 km.

As the aftershock monitoring arrays such as $\mathrm{KG}$ and $\mathrm{PH}$ become available, the aftershock locations involve smaller uncertainty than that of previous earthquakes and the Pohang earthquake by a factor of 7 or better (Figure 3). The epicentral $p d f s$ of five large aftershocks $\left(\mathrm{M}_{\mathrm{L}}\right.$ 3.5-4.3) are also located within 1-2 km of both the Pohang earthquake and the wells (Figure $3 \mathrm{~b}$ ). Relocated aftershocks extend farther to the northeast and southwest of the injection well locations (Figure 3b), consistent with the slip distribution imaged by InSAR data (Song and Lee, 2019) . The aftershocks are distributed within a depth range of $1.2-6.8 \mathrm{~km}$, and peaked in a depth range between the well tip and the depth of the Pohang earthquake (4.2-4.8 km; Figure 3c). The majority of the aftershocks (86\%) are concentrated in the granodiorite basement (Figure 3c; Lee et al., 2015). 


\section{Poroelastic modeling against hydraulic diffusivity}

The stress perturbation due to fluid injection highlights how the poroelastic response of the media may potentially cause the Pohang earthquake and previous ones between January 2016 and 15 November 2017. As described in Section 2, we explore a wide range $\left(10^{-7}\right.$ to $\left.10^{3} \mathrm{~m}^{2} / \mathrm{s}\right)$ of

262 values for the both $D_{\text {bed }}$ and $D_{\mathrm{dmz}}$ with fixed poroelastic parameters $\left(\nu, v_{\mathrm{u}}, B, \alpha, G\right.$, and $\left.\eta\right)$ and $\mu$. 263 We sample stress changes and $\Delta p$ at the projected location of the mainshock hypocenter (KGC, 264 2019; Woo et al., 2019) onto the fault plane (Figure 4b, yellow star).

Figure 5 illustrates the temporal evolution of the stresses and pore pressure changes $\left(\Delta C F S, \Delta \sigma_{\mathrm{n}}\right.$, $\Delta \tau$ and $\Delta p$ ) for various $D_{\text {bed }}$ and $D_{\mathrm{dmz}}$ during the fluid injection and flowback history (Figure 2). We examine the first-order trends of $\Delta C F S, \Delta \sigma_{\mathrm{n}}, \Delta \tau$ and $\Delta p$ by applying a Gaussian lowpass filter with a standard deviation of 2 months (Figure 5, colored lines). The filter removes sharp peaks or steps in the stress change curves which can be associated with the injection and

272 flowback practices (Figure 5, grey lines). For the four cases, the filtered stress chang curves clearly show different amplitudes and gradients at the time of the Pohang earthquake, highlighting the importance of $D_{\text {bed }}$ and $D_{\mathrm{dmz}}$ in the earthquake occurrence (Figure 5). on 15 November 2017. $\Delta C F S, \Delta \sigma_{\mathrm{n}}, \Delta \tau$ and $\Delta p$ shown in Figure 5a are computed for a

277 homogeneous model (i.e., $D_{\text {bed }}=D_{\mathrm{dmz}}=5 \times 10^{-4} \mathrm{~m}^{2} / \mathrm{s}$ ), and those in Figure $5 \mathrm{~b}$ are for a model 
278 involving a fault structure $\left(D_{\text {bed }}=5 \times 10^{-4} \mathrm{~m}^{2} / \mathrm{s} ; D_{\mathrm{dmz}}=1 \times 10^{-2} \mathrm{~m}^{2} / \mathrm{s}\right)$. When $D$ is homogeneous

279 and low (i.e. $D_{\text {bed }}=D_{\mathrm{dmz}}=5 \times 10^{-4} \mathrm{~m}^{2} / \mathrm{s}$ ), the overall trend of $\triangle C F S$ closely follows the trend of $280 \Delta p$, which increases substantially after injection D16 (Figure 5a). Because of the low $D$ values, 281 the time intervals between subsequent injection events are too short for the stresse changes built 282 up by previous injection events to fully dissipate. The value of $\triangle C F S$ is 2.1 bar on 15 November 2832017 (Figure 5a).

In the case of a permeable fault damage zone $\left(D_{\mathrm{dmz}}=10^{-2} \mathrm{~m}^{2} / \mathrm{s}\right)$, we obtain a temporal

285 history of the $\triangle C F S$ amplitude similar to that obtained for the homogeneous model (Figure 5a), 286 but with slightly reduced magnitude (Figure 5b). The amplitudes of both $\Delta p$ and $\Delta \sigma$ decrease 287 because of fast diffusion within the fault damage zone. As a result, $\Delta \tau$ contributes to $\triangle C F S$ to a 288 greater degree. We observe a trend for increasing $\Delta \tau$ close to the time of the mainshock whereas $289 \Delta p$ shows a slightly decreasing trend (Figure $5 \mathrm{~b}$ ). The value of $\triangle C F S$ is 1.3 bar on 15 November 2902017 (Figure 5b).

Notably, in Figures 5a and b, we observe that the level of $\triangle C F S$ drops and then rises, 292 with a large negative peak in January-February 2017; this feature stems from the practice of 293 alternating injection at PX-1 and PX-2. Figure 6 shows the temporal changes in $\triangle C F S$ caused by 294 each well computed using the same values of $D$ as Figure 5b. Figure 6 clearly shows that the 295 drop in $\triangle C F S$ in January-February 2017 is closely associated with the injection D16 at PX-1 296 when the largest volume of fluid is injected (Figure 2). $\Delta \tau$ shows an increasing trend at injection MA17 (Figures 5a and b). Generally, $\Delta \tau$ 298 decreases with injection at PX-1 (i.e., D16 and A17; Figure 2), and increases with injection at 299 PX-2 (JF16, MA17 and S17; Figure 2). These opposite responses in PX-1 and PX-2 are observed 
more clearly in unfiltered $\Delta \tau$ (Figure S5). Figure S5 shows unfiltered $\Delta C F S, \Delta \sigma_{\mathrm{n}}, \Delta \tau$ and $\Delta p$ for individual well and both wells. Figures $\mathrm{S} 5 \mathrm{~b}$ and $\mathrm{c}$ show $\Delta C F S, \Delta \sigma_{\mathrm{n}}, \Delta \tau$ and $\Delta p$ involving the injection practice at PX-1 or PX-2 with same $D_{\text {bed }}$ and $D_{\mathrm{dmz}}$ of Figure 5a. Similarly, Figures S5e and f show $\Delta C F S, \Delta \sigma_{\mathrm{n}}, \Delta \tau$ and $\Delta p$ of Figure 5b. In December 2016 and early August 2017, $\Delta \tau$ is decreased sharply by injections at PX-1 (D16 and A17; Figures S5b and e). In late August 2017, flowback following injection A17 rapidly increases $\Delta \tau$ by a similar amount of the ealier decrease (Figures S5b and e). All injections at PX-2 increase $\Delta \tau$ in January-February 2016, March-April 2017 and September 2017 (Figures S5c and f). Because the distance between the stress sampling point and PX-2 is larger than that with PX-1 (Figure 4), observed changes in $\Delta \tau$ of PX-2 in response to all injections (Figures S5c and f) are smaller than those of PX-1 (Figures S5b and e).

Also, we can see that filtered $\triangle C F S$ in the period after the negative peak (from May 2017 to February 2018) is larger than in the period January-August 2016 (Figures 5a and b). This suggests that, for the mainshock occurrence on 15 November 2017, $\triangle C F S$ should be its largest during the period from the beginning of injection (29 January 2016) to that day. This could be a key condition for constraining $D$ and reconciling it with the timing of the mainshock, which is delayed by $\sim 2$ years after the first injection in January 2016 and 58 days after the last injection in September 2017. This feature was not captured by previous studies based on hydraulic diffusion modeling (Ellsworth et al., 2019; KGC, 2019).

On the other hand, Figure $5 \mathrm{c}$ shows a case in which $D_{\mathrm{dmz}}\left(=10 \mathrm{~m}^{2} / \mathrm{s}\right)$ is much higher than $D_{\text {bed, }}$ and higher than the value used in Figure $5 \mathrm{~b}$ by a factor of 3 . For this case, the diffusion speed within the fault damage zone is too fast to cause $\triangle C F S$ to have its largest amplitude on 15 November 2017. $\triangle C F S$ on 15 November 2017 is 0.24 bar, less than the local peak amplitude in May 2016 (0.25 bar; Figure 5c). 
The last example is a case involving extremly low $D_{\text {bed }}\left(=1 \times 10^{-6} \mathrm{~m}^{2} / \mathrm{s}\right)$ with a permeable

324 fault damage zone $\left(D_{\mathrm{dmz}}=1 \times 10^{-2} \mathrm{~m}^{2} / \mathrm{s}\right.$; Figure $\left.5 \mathrm{~d}\right)$. The most prominent feature in this case is

325 that $\Delta p$ is nearly zero in the entire period considered, because the characteristic time from the

326 wells to the sampling point is very long. Only $\Delta \tau$ changes significantly and thus affects $\Delta C F S$.

327 Although $\triangle C F S$ is increasing on 15 November 2017, the amplitude of $\triangle C F S$ is still smaller than

328 in the period January-August 2016. In short, $\triangle C F S$ does not reach its maximum value at the time

329 of the mainshock if the fault damage zone becomes more permeable $\left(D_{\mathrm{dmz}}=1 \times 10^{1} \mathrm{~m}^{2} / \mathrm{s}\right.$; Figure

$3305 \mathrm{c})$, or if the bedrock extremely impermeable $\left(D_{\text {bed }}=1 \times 10^{-6} \mathrm{~m}^{2} / \mathrm{s}\right.$; Figure $\left.5 \mathrm{~d}\right)$.

4.2 Search for possible ranges of $D$ for Pohang earthquake occurrence

By examining the temporal evolution of stress changes depending on representative $D$ -

334 values (Figure 5), we can determine possible ranges of $D_{\text {bed }}$ and $D_{\mathrm{dmz}}$ to reconcile the delay

335 between the timing of the Pohang earthquake and the peak stress change induced by the injection.

336 As described in Section 4.1, we use examples highlighted in Figure 5 as a guide to search for 337 ranges of $D_{\text {bed }}$ and $D_{\mathrm{dmz}}$ that are critical to induce the Pohang earthquake. Specifically, the range

338 of $D_{\text {bed }}$ and $D_{\mathrm{dmz}}$ can be defined if the amplitude of $\triangle C F S$ on the day of the mainshock (15

339 November 2017) is the largest from the beginning of the injection (29 January 2016) to that day.

Figure 7 illustrates a classification of the models consisting of the ranges of $D_{\text {bed }}$ and $D_{\mathrm{dmz}}$

$341 \quad\left(10^{-7}-10^{3} \mathrm{~m}^{2} / \mathrm{s}\right)$. Pairs of values lying on the diagonoal line shown represent homogenous model.

342 The zone above that diagonal line represents models with more permeable fault damage zone

343 than the bedrock (i.e., $D_{\text {bed }}<D_{\mathrm{dmz}}$ ), whereas the zone below represents those with more

344 impermeable fault damage zone than the bedrock (i.e., $D_{\text {bed }}>D_{\text {dmz }}$ ). The thickness of the fault 
345 damage zone is fixed as $85 \mathrm{~m}$, following the value of Ellsworth et al. (2019) and KGC (2019) for

346 the purpose of benchmarking (Figure $4 \mathrm{~b}$ ). A tradeoff between the thickness and $D_{\mathrm{dmz}}$ does not

347 affect the temporal evolutions of $\Delta C F S, \Delta \sigma_{\mathrm{n}}, \Delta \tau$ and $\Delta p$ when the sampling point is within the

348 damage zone (Figure 4b).

349

350

351

352

353

354

355

356

357

358

359

360 361 that for the mainshock $\left(1 \times 10^{-4}-5 \times 10^{-3} \mathrm{~m}^{2} / \mathrm{s}\right)$ in Figure 7 .

projected location of the hypocenter of the Mw 3.2 earthquake onto the fault (Figure 4) in order

to validate the values of $D_{\text {bed }}$ and $D_{\mathrm{dmz}}$ based on the mainshock (Figure S6). For this, the criterion is changed to that the amplitude of $\triangle C F S$ on the day of the Mw 3.2 earthquake (15 April 2017) is the largest from the beginning of the injection (29 January 2016) to that day. Similarly, we consider only the values when $D_{\text {bed }} \leq D_{\text {dmz }}$. Figure S6 shows estimates of $D_{\text {bed }}$ and $D_{\mathrm{dmz}}$ for the Mw 3.2 earthquake, and they are quite similar to the values for the Pohang earthquake shown in Figure 7. In particular, the range of $D_{\text {bed }}$ in Figure S6, which is $2 \times 10^{-4}-5 \times 10^{-3} \mathrm{~m}^{2} / \mathrm{s}$, encloses

Two sets of $\Delta C F S, \Delta \sigma_{\mathrm{n}}, \Delta \tau$ and $\Delta p$ caused by the injections at PX-1 and PX-2 are calculated on the fault plane, defined as in Figure 4 . The values of $D_{\text {bed }}$ and $D_{\mathrm{dmz}}$ are chosen as 5 
$366 \times 10^{-4} \mathrm{~m}^{2} / \mathrm{s}$ and $1 \times 10^{-2} \mathrm{~m}^{2} / \mathrm{s}$, respectively, the same as for those in Figure $5 \mathrm{~b} . \Delta C F S, \Delta \sigma_{\mathrm{n}}, \Delta \tau$ and $367 \Delta p$ as affected by injection at PX-1 (PX-2) are presented in Figures 8a-d (e-h). Figure 9a shows 368 the sum of $\triangle C F S$ computed for the two wells (Figures 8a and e).

The distributions of $\Delta p$ and $\Delta \sigma_{\mathrm{n}}$ have spherical symmetry around the injection point on the fault plane (Figures 8c, d, g and h). For both wells, the values of $\Delta p$ are positive (Figures 8c and $\mathrm{g}$ ). $\Delta \sigma_{\mathrm{n}}$ by PX-2 is expected to be compressive (Figure $8 \mathrm{~h}$ ) because the last injection was performed at PX-2 (Figure 2). On the other hand, $\Delta \sigma_{\mathrm{n}}$ by PX-1 is positive with smaller amplitudes than by PX-2 (Figure 8d) because of the flowback following injection that occurred in August 2017 (Figure 2).

The distribution of $\Delta \tau$ shows two lobes with opposite polarities with an axis of symmetry along the rake of the fault (Figures $8 \mathrm{~b}$ and $\mathrm{f}$ ). $\Delta \tau$ by the injection at PX-2 is negative toward the rake (Figure 8f). On the other hand, the injection at PX-1 generates the reverse pattern, with positive polarity toward the rake, and with much smaller amplitudes than those at PX-2 (Figure 8b). The flowback at PX-1 in August 2017 generates the negative polarity of $\Delta \tau$ toward the rake (Figure 8b).

$\Delta p$ by PX-1 contributes to $\triangle C F S$ the most (Figures $8 \mathrm{a}$ and c). On the contrary, $\Delta \tau$ and $\Delta \sigma_{\mathrm{n}}$ contiribute most to $\triangle C F S$ in the case of the injection at PX-2 (Figures $8 \mathrm{e}-\mathrm{h}$ ). The degree of contribution of $\Delta \sigma_{\mathrm{n}}, \Delta \tau$ and $\Delta p$ on the $\Delta C F S$ depends on factors such as the injected volume of fluid, hydraulic diffusivity, distance from the well to the fault and time of injection.

\subsection{Temporal evolution of $\triangle C F S$}


387 Figure 10 shows the variations of $\triangle C F S$ amplitude for all 21 cases (grey lines) that satisfy the $388 \triangle C F S$ amplitude criterion (Figure 7, red squares) and have $D_{\mathrm{dmz}} \geq D_{\text {bed. }}$ With the determined 389 values of $D$, all $\triangle C F S$ values are maximized on 15 November 2017 for the period from 29 390 Januaray 2016 to that day. $\triangle C F S$ starts with 0.2 bar in January-February 2016 and reaches its 391 maximum, at 0.3-2.2 bar, on 15 November 2017 (Figure 7). The 25th pencentile, median and 392 75th percentile are 0.4, 0.6 and 1.1 bar, respectively, on 15 November 2017 (Figure 10, red 393 dashed and solid lines). The range of 0.4-1.1 bar is much lower than the coseismic stress drop of

394 20 bar (Song and Lee, 2019), but much greater than the stress perturbations from natural 395 sources (0.001-0.004 bar; Johnson et al., 2017).

Figure 9a shows total $\triangle C F S$ reflecting the effects of both PX-1 and PX-2 (computed with the same values of $D$ as Figure $5 b$ ), compared with the locations of earthquakes projected onto the fault plane. These earthquakes are associated with injection at PX-2 (KGC, 2019; Woo et al., 2019), with the three largest that occurred during injection events at PX-2 (JF16, MA17 and S17) 402 shown as colored and crossed circles (Figure 9a). the positive and negative zones occurs roughly at the mid-point of the two wells (Figure 9a). The mainshock hypocenter determined by KGC (2019) is located in the positive region, southwest from PX-1 and PX-2 (Figure 9a, blue crossed circle). Hong et al. (2018) also showed that the 407 epicenter of the mainshock is located west of the well positions (Figure 3). Overall, the 408 earthquakes occurred most often in the region with positive $\Delta \tau$ (Figures $8 \mathrm{f}$ and 9). 
We also calculate $\triangle C F S$ with an impermeable layer at the center of the fault, to reflect the

410 possible existence of a fine-grained fault gouge (Figure 4b). The thickness and $D$ of this core

411 ( $\left.D_{\text {core }}\right)$ are $10 \mathrm{~m}$ and $10^{-6} \mathrm{~m}^{2} / \mathrm{s}$, respectively, following the values reported by Ellsworth et al.

412 (2019) and KGC (2019). Note that the amplitude of $\triangle C F S$ is increased for the model with the

413 core (Figure 9b). Nevertheless, the effect of including this impermeable core in our model

414 (Figure 9b) appears minor because the patterns of $\triangle C F S$ amplitude are rather similar between the 415 models with and without it (Figure 9). The distributions of $\Delta \sigma_{\mathrm{n}}, \Delta \tau$ and $\Delta p$ for the two models are 416 also similar with slight differences in amplitude (Figure S7).

Figure 11 shows $\triangle C F S$ on the fault plane at two different times when the Mw 1.6 and 3.2 earthquakes occurred on 7 February 2016 and 15 April 2017, respectively. Because the focal

419 mechanisms of these earthquakes are similar to that of the mainshock, the receiver fault 420 geometry is kept the same in our modeling. The strike, dip and rake of the Mw 1.6 earthquake 421 are $208^{\circ}, 58^{\circ}$ and $156^{\circ}$, respectively, and those of the Mw 3.2 earthquake are $215^{\circ}, 58^{\circ}$ and $128^{\circ}$, 422 respectively (KGC, 2019; Woo et al., 2019). $\triangle C F S$ regions (Figure 11a). Also, the locations of the smaller earthquakes are clustered in this boundary, with some in the positive region (Figure 11a). On the other hand, the projected

426 locations of the Mw 3.2 earthquake and smaller earthquakes correlate well with the region of 427 positive $\triangle C F S$ amplitude (Figure 11b). The Mw 3.2 earthquake is located roughly in the mid-

428 point between the wells, close to a spot where the amplitude of $\triangle C F S$ is highest (Figure 11b).

429 The amplitude of $\triangle C F S$ at the nearest grid point is 3.2 bar (Figure 11b). Also, at that point 430 location, $\Delta \sigma_{\mathrm{n}}, \Delta \tau$ and $\Delta p$ are $-2.5,2.0$ and 4.6 bar, respectively. Therefore, $\Delta \tau$ and $\Delta p$ play a 431 critical role in inducing the Mw 3.2 earthquake. 


\section{Discussion}

The delayed occurrence of the Pohang earthquake, by 58 days after the last injection S17 or 2 years after the first injection JF16, is not explained by a model with high $D_{\text {bed }}$ (e.g., $D_{\text {bed }}=10^{-2}$ $\mathrm{m}^{2} / \mathrm{s}$ used in Ellsworth et al., 2019, and KGC, 2019). With $D_{\text {bed }}=10^{-2} \mathrm{~m}^{2} / \mathrm{s}$ and $D_{\mathrm{dmz}}=10^{-2} \mathrm{~m}^{2} / \mathrm{s}$, $\triangle C F S$ is maximized in January-April 2017 and decreasing on 15 November 2017 (Figure S3). To understand the delayed response, we suggest that low $D_{\text {bed }}$ values, ranging from $1 \times 10^{-4}-5 \times$

$44010^{-4} \mathrm{~m}^{2} / \mathrm{s}$ (if $D_{\mathrm{bed}} \leq D_{\mathrm{dmz}}$ ) effectively slow the diffusion of $\Delta p$ (Figure 7). A more elaborate 441 poroelastic modeling scheme showed an increasing trend for $\triangle C F S$ at the time of the mainshock 442 (Chang et al., 2020), similar to our study results. Our estimated range of $D_{\text {bed }}$ is within the endmember estimates from the numerical simulation, with high permeability range $\left(1 \times 10^{-15}-5 \times\right.$ $10^{-14} \mathrm{~m}^{2}$ ) or a value for $D$ of $1-40 \mathrm{~m}^{2} / \mathrm{s}$ in a confined zone around the well position in Pohang (at most $100 \mathrm{~m}$; see Figure 4.7 of Yoo (2018)) and low permeability $\left(4-7 \times 10^{-21} \mathrm{~m}^{2}\right)$ or a value for $D$ of 3-6 $\times 10^{-6} \mathrm{~m}^{2} / \mathrm{s}$ for the intact granodiorite gneiss (Morrow et al., 1994).

Although our modeling is based on the classical friction model (i.e., constant static and dynamic coefficients), the rate-and-state friction model can be used to rationalize the observed two-month delay between the last injection and the Pohang earthquake. Dieterich (1994) established a concept of seismicity rate on the rate-and-state friction model. The rate-and-state friction can delay an increase in the seismicity rate compared to an earlier peak of $\triangle C F S$

452 (Dieterich, 1994; Segall and Lu, 2015). In particular, Segall and Lu (2015) observed that the 
454 the delay due to the rate-and-state friction is sensitive to the empirical constitutive frictional

455 parameter and the background stress state, both of which have a large uncertainty.

In our analysis, we show that the Pohang earthquake can occur when the amplitude of $\triangle C F S$ reaches $0.4-1.1$ bar (Figure 10, 25th and 75th percentiles). Given the set-up of our model, the range of $0.4-1.1$ bar is likely to be a threshold for the occurrence of this earthquake at the hypocenter where the rupture begins at the fault. This range is broadly bounded by the average stress drop of $\sim 20$ bar constrained by static slip inversion using InSAR data (Song and Lee, 2019) and the stress field created by natural processes such as hydraulic surface loading (i.e., rain and snow), thermal expansion, atmospheric pressure, and tide (Johnson et al., 2017). For instance, the three most significant factors in California, USA, are the hydraulic $(\triangle C F S \approx 0.015$ bar), atmospheric (0.004 bar), and thermoelastic sources (0.001 bar; Johnson et al., 2017). Also, 467 our $\triangle C F S$ amplitude range is substantially higher than the static $\triangle C F S$ caused by the $2016 \mathrm{Mw}$ 5.5 Gyeongju earthquake (South Korea's largest earthquake during the instrumental period; Kim et al., 2017; Grigoli et al., 2018) which occurred on 12 September 2016, $42 \mathrm{~km}$ from the epicenter of the Pohang earthquake. The static $\triangle C F S$ was only 0.005 bar at the hypocenter of the

4712017 Pohang earthquake (Grigoli et al., 2018; Hong et al., 2018). This amplitude range (0.4-1.1

472 bar) that we have determined is higher than that of other studies, which may imply that the 473 poroelastic stressing due to injection is the most critical mechanism affecting the occurrence of 474 the earthquake. In addition, we demonstrated in Figure 6 that, for either individual well, injection at PX-2 is a larger contributing factor to the occurrence of the Pohang earthquake. This is not 
476

477

478

479

480

481

482

483

484

485

486

487

488

489

490

491

492

493

494

495

496

497

surprising because PX-2 has a larger volume of injected fluid $\left(1,695 \mathrm{~m}^{3}\right.$ at PX-1 and 4,146 $\mathrm{m}^{3}$ at PX-2; Figure 2).

5.3 Amplitude of $\triangle C F S$ and magnitude of the Pohang earthquake

The ratio of the induced stress change (or $\Delta p$ ) to the stress drop (e.g. Foulger et al., 2018; Gupta, 2002) can be considered a measure of the anthropogenic contribution to the Pohang earthquake occurrence. In many cases, induced earthquakes are associated with much smaller anthropogenic stress change than pre-existing tectonic stress (Gupta, 2002). Our modeling results show that the $\triangle C F S$ in November 2017 peaked at $\sim 0.6$ bar (median), bounded by 0.4 and 1.1 bar (25th and 75th percentiles, respectively; Figure 10). For the Pohang earthquake, the ratio of $\triangle C F S$ to the observed stress drop ( 20 bar; Song and Lee, 2019) is 3\% for the median or a range of 2-6\% for the percentiles.

The Mw 5.5 Pohang earthquake does not follow the empirical relationship between the maximum magnitude and total volume of injected fluid proposed by McGarr (2014).

Considering the total fluid volume injected at the Pohang EGS, the predicted maximum magnitude (M MAX) is considerably lower (3.5; Grigoli et al., 2018; Kim et al., 2018). Thus, the Mw 5.5 event in Pohang is clearly an outlier in this prediction model (McGarr, 2014). In that model, $\Delta p$ induced by an injection is assumed to be equal to one half of the stress drop. As the ratio of $\triangle C F S$ to the inferred stress drop is low for the Pohang earthquake, $\mathrm{M}_{\mathrm{MAX}}$ may be underestimated. Furthermore, if the rupture propagates beyond the nucleated zone as a result of $\Delta p$, the magnitude may become even greater (Galis et al., 2017). Also, recent studies by Ellsworth et al. (2019), KGC (2019) and Woo et al. (2019) support this viewpoint. Foulger et al. 
(2018) explored datasets from 218 cases, and reported a few outliers from the relationship proposed by McGarr (2014).

We suggest that fluid injection to the basement probably enhanced the release of tectonic stress in Pohang, similar to a case in Oklahoma, USA (Hincks et al., 2018). The focal depth of the Pohang earthquake is close to the tip of the injection well (Figure 3c), and its depth is well within the range that exhibits slip-weakening behavior (Marone and Scholz, 1988; Scholz, 1998). Most aftershocks (95\%) are also distributed through the basement layer (Figure 3c). Injection to the basement may thus be another prerequisite contributing to large-magnitude events such as the Pohang earthquake.

The low values of $D_{\text {bed }}\left(1 \times 10^{-4}-5 \times 10^{-4} \mathrm{~m}^{2} / \mathrm{s}\right.$; Figure 7 , red squares $)$ may be valid if slow fluid diffusion is also applicable to earthquakes before the mainshock. As Figure S6 shows, the estimated ranges of $D_{\text {bed }}$ and $D_{\mathrm{dmz}}$ for the Mw 3.2 earthquake are quite similar to those for the mainshock (Figure 7).

\subsection{Previous earthquakes in response to poroelastic stresse changes}

Although the location of the Mw 3.2 earthquake has high uncertainties in depth (at most $\pm 10 \mathrm{~km}, 2 \sigma$ ) and horizontal distance (at most $5 \mathrm{~km}, 95 \%$ ) due to the limited presence or complete absence of nearby stations, the epicenters determined by KGC (2019) and Woo et al. (2019) are very close to the median of our epicentral $p d f$ (Figure 3a). The projected location of the Mw 3.2 earthquake, and of smaller magnitude ones, onto the fault plane correlates well with the region of positive $\triangle C F S$ (Figure 11b). That region around the Mw 3.2 earthquake is a result of $\Delta \tau$ and $\Delta p$ 
due to injection at PX-1 and of $\Delta \tau$ due to injection at PX-2 (Figures S8b, c and f).

We also note that the locations of the Mw 1.6 earthquake and various smaller ones correlate poorly with the positive $\triangle C F S$ region (Figure 11a). The observed stress perturbation for this event is small (Figure 11a) and, thus, an ambient tectonic stress or the mud loss to the amount of $650 \mathrm{~m}^{3}$ at a depth of $3.8 \mathrm{~km}$ in PX-2 in October-November 2015 (KGC, 2019) may have affected the pattern of $\triangle C F S$ to a greater degree.

\subsection{Heterogeneity of hydraulic property near/at the wells}

Previous studies (Yoo, 2018; KGC, 2019) suggested that PX-1 and PX-2 have different hydraulic properties. While the critical pressure (attained when the ratio of the injection rate to the injection pressure is changed significantly) of PX-1 is only 200 bar (wellhead pressure), the critical pressure of PX-2 is 800 bar during its injection events (Park et al., 2017; KGC, 2019). KGC (2019) interpreted that such a difference might arise from a difference in the fracture network created by high-pressure stimulation. Furthermore, Yoo (2018) observed high permeability that was dependent on pore-pressure, up to $1 \times 10^{-15}-5 \times 10^{-14} \mathrm{~m}^{2}\left(D=1-40 \mathrm{~m}^{2} / \mathrm{s}\right)$ in the region closest to the well. Although well-dependent and distance-dependent heterogeneities can change the fields of $\Delta C F S, \Delta \sigma_{\mathrm{n}}, \Delta \tau$ and $\Delta p$, such factors may not be essential to explain the observed delay of the mainshock (58 days after the last injection and about two years after the first injection) if the hypocenter is sufficiently distant from the nearwell zone. The mainshock's hypocenter is several hundred meters from the wells (KGC, 2019; Woo et al., 2019). The observed high permeability during injection only persists for, at most, 2 days at the wells and recovers to its initial low permeability (Yoo, 2018). 


\section{Summary}

The 2017 Mw 5.5 Pohang earthquake in South Korea was the first reported and largestmagnitude induced earthquake associated with the exploitation of deep geothermal energy, and with a relatively small volume of injected fluid. Considering the total fluid volume injected at the Pohang EGS, the predicted maximum magnitude for the Pohang earthquake is considerably low at 3.5. Furthermore, the occurrence of such a large earthquake $\sim 2$ months after the final EGS operation questions how critically the injected fluid affects the stress on a fault close to its failure conditions. In this study, we determine the range of the hydraulic diffusivities for the bedrock and the fault damage zone based on the criterion that the Coulomb failure stress should reach its maximum value on the day of the Pohang earthquake. The observed delay between each injection event and the Pohang earthquake on 15 November 2017 can be explained by a low hydraulic diffusivity of the bedrock values in the range $1 \times 10^{-4}-5 \times 10^{-4} \mathrm{~m}^{2} / \mathrm{s}$ with the fault damage zone structure $\left(5 \times 10^{-6}-1 \times 10^{0} \mathrm{~m}^{2} / \mathrm{s}\right)$. In this range, the fluid injection can cause a Coulomb failure stress change of up to $0.4-1.1$ bar, although this is still much lower than the average of the stress drop ( 20 bar; Song and Lee, 2019).

\section{Appendix A: Hypocenter determination}

We sample the $p d f$ s of the hypocenters using the Bayesian hierarchical multiple-event location method (bayesloc), applying corrections to the travel-time curve (i.e., one-dimensional velocity model) and different weights to the measurements of the arrival times (Myers et al., 2007). This 
562 probabilistic approach permits the resolution of absolute location and is robust against poor 563 network configuration (Myers et al., 2007). In this study, eight Markov chains are used to sample 564 the $p d f$ with 10,000 iterations, resulting in 4,000 chains at the final iteration for an individual earthquake. The resulting posterior samples are used to estimate marginal distributions, such as epicenters and probability regions (Myers et al., 2007).

A total of 311 earthquakes that occurred between 22 December 2016 and 17 February 2018 are analyzed for probabilistic earthquake relocation (Figure 3). We use two earthquake catalogues that were available from the Korea Meteorological Administration (KMA) and the study by Kim et al. (2018). Kim et al. (2018) reported six foreshocks and 210 aftershocks in the 3 hours immediately after the Pohang earthquake. Using the bayesloc method for the hypocenters of the aftershocks improves the accuracy of the locations of the mainshock and also the previous earthquakes. Networks KS, KN, KG, K18, and G18 recorded the Pohang earthquake, and networks PH and KG (temporary stations) only provided waveforms of the aftershocks, since they were deployed a few days after the Pohang earthquake (Figure 1). See Figure S9 for a timetable of the seismic data. In this study, we use the one-dimensional velocity model of KGC (2019), which is a composite based on an active source survey less than $5 \mathrm{~km}$ from the injection wells for constraining the shallow-depth structure and the regional velocity model of Kim et al. (2011) for the deep structure (Figure S10). To avoid interference due to diffracted waves from the Moho (i.e., $P n$ and $S n$ ), $P$ and $S$ wave arrival times from stations within $80 \mathrm{~km}$ of the source region are manually measured from the vertical and transverse components of their raw seismic waveforms, respectively.

K18 and G18, located at or near the EGS site (Figure 1), recorded the Pohang earthquake, and they are critical for reducing the uncertainties on its focal depth and epicenter location to less 
585 than $1 \mathrm{~km}$. Excluding their data (i.e., using only that from the permanent networks KS, KG, and

$586 \mathrm{KN}$ in Figure 1) results in an uncertainty exceeding $1 \mathrm{~km}$ for the epicenter location, and of up to

$5878 \mathrm{~km}$ for the focal depth.

588 The standard deviation of the differences between the measured arrival times and

589 fitted straight lines are 0.02 s for $\boldsymbol{P}$ wave at stations near to the EGS (stations K18 and G18)

590 and $0.18 \mathrm{~s}$ for $\boldsymbol{P}$ wave and $0.66 \mathrm{~s}$ for $S$ wave at distant stations ( $<80 \mathrm{~km} ;$ Figure $\mathrm{S} 11)$. The

591 deviations from the straight line indicate a level of three-dimensional heterogeneity in the

592 medium or errors in the measurements, contributing to an epicentral uncertainty of the

593 order of $1 \mathrm{~km}$. 
594 Table 1. List of poroelastic parameters except for the hydraulic diffusivity.

\begin{tabular}{|l|l|l|l|}
\hline Name & Range & Used value $^{\dagger}$ & Note \\
\hline Shear modulus $(G)$ & $\begin{array}{l}19-24 \mathrm{GPa}(\text { granite } \\
\left.\text { at } T=30-150^{\circ} \mathrm{C}\right)^{\mathrm{a}}\end{array}$ & $22 \mathrm{GPa}$ & Median \\
\hline $\begin{array}{l}\text { Skempton's } \\
\text { coefficient }(B)\end{array}$ & $\begin{array}{l}0.5-0.9 \text { (crustal }^{\mathrm{b}} \\
\text { rock) })^{\mathrm{b}, \mathrm{d}}\end{array}$ & 0.75 & Median \\
\hline $\begin{array}{l}\text { Drained Poisson's } \\
\text { ratio }(v)\end{array}$ & - & $0.25^{\mathrm{d}}$ & Granite \\
\hline Biot coefficient $(\alpha)$ & $\begin{array}{l}0.20,0.25 \text { and } 0.32 \\
\left(\text { granite when } P_{\mathrm{e}}=\right. \\
1 \text { kbar) }\end{array}$ & 0.25 & Median \\
\hline $\begin{array}{l}\text { Frictional } \\
\text { coefficient }(\mu)\end{array}$ & $0.6-0.85^{\mathrm{f}}$ & $0.6^{\mathrm{g}}$ & $\begin{array}{l}\text { Measurement of rock } \\
\text { from PX-2 }\end{array}$ \\
\hline $\begin{array}{l}\text { Dynamic viscosity } \\
(\eta)\end{array}$ & - & $\begin{array}{l}0.15 \times 10^{-3} \\
\text { Pa }^{\mathrm{i}}\end{array}$ & $T=170{ }^{\circ} \mathrm{C}^{\mathrm{h}}$ \\
\hline
\end{tabular}

$595 T^{\dagger}$ Values used in the modeling. ${ }^{a}$ Hughes and Jones (1950). ${ }^{b}$ Detournay and Cheng (1993). ${ }^{c}$ Hart

596 and Wang (1995). ${ }^{\mathrm{d}}$ Rice and Cleary (1976). ${ }^{\mathrm{e}}$ Coyner (1984). ${ }^{\mathrm{f}}$ Byerlee (1978). ${ }^{\mathrm{g}} \mathrm{K} w o n$ et al.

597 (2018). ${ }^{h}$ Lee et al. (2010). ${ }^{\mathrm{i}}$ Wonham (1967). $T$-Temperature. $P_{\mathrm{e}}$-Effective confining pressure. 


\section{Figures}

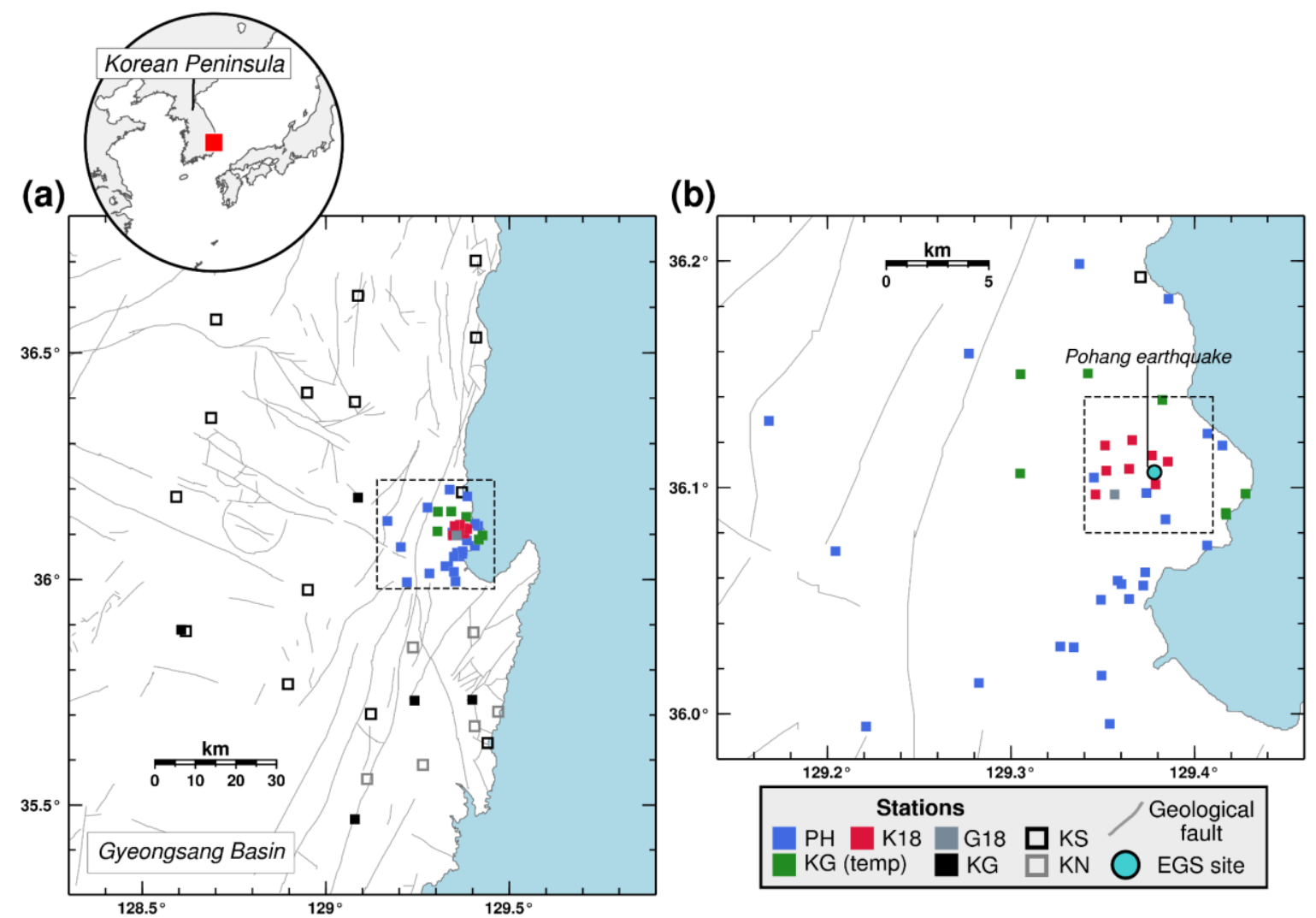

Figure 1. Map of the study region. (a) Map including all seismic stations used in the analysis

601 with an inset showing East Asia. Station networks KS, KG, and KN are permanently deployed, while PH, K18, G18, and KG (temp) are temporarily deployed for aftershock monitoring. The area enclosed in the dashed box is shown in (b), and gray lines represent faults. (b) Map showing the temporary stations and one permanent station PHA2 (network KS). The network G18 consists of station POH01. G18 - Grigoli et al. (2018). K18 - Kim et al. (2018). KG-Korea Institute of Geoscience and Mineral Resources. KS - Korea Meteorological Administration. KN-Korea Hydro \& Nuclear Power Co., Ltd. PH—Seoul National University and Pukyong National University. EGS—Enhanced geothermal system. See Figure S2 for stations with station ID. 


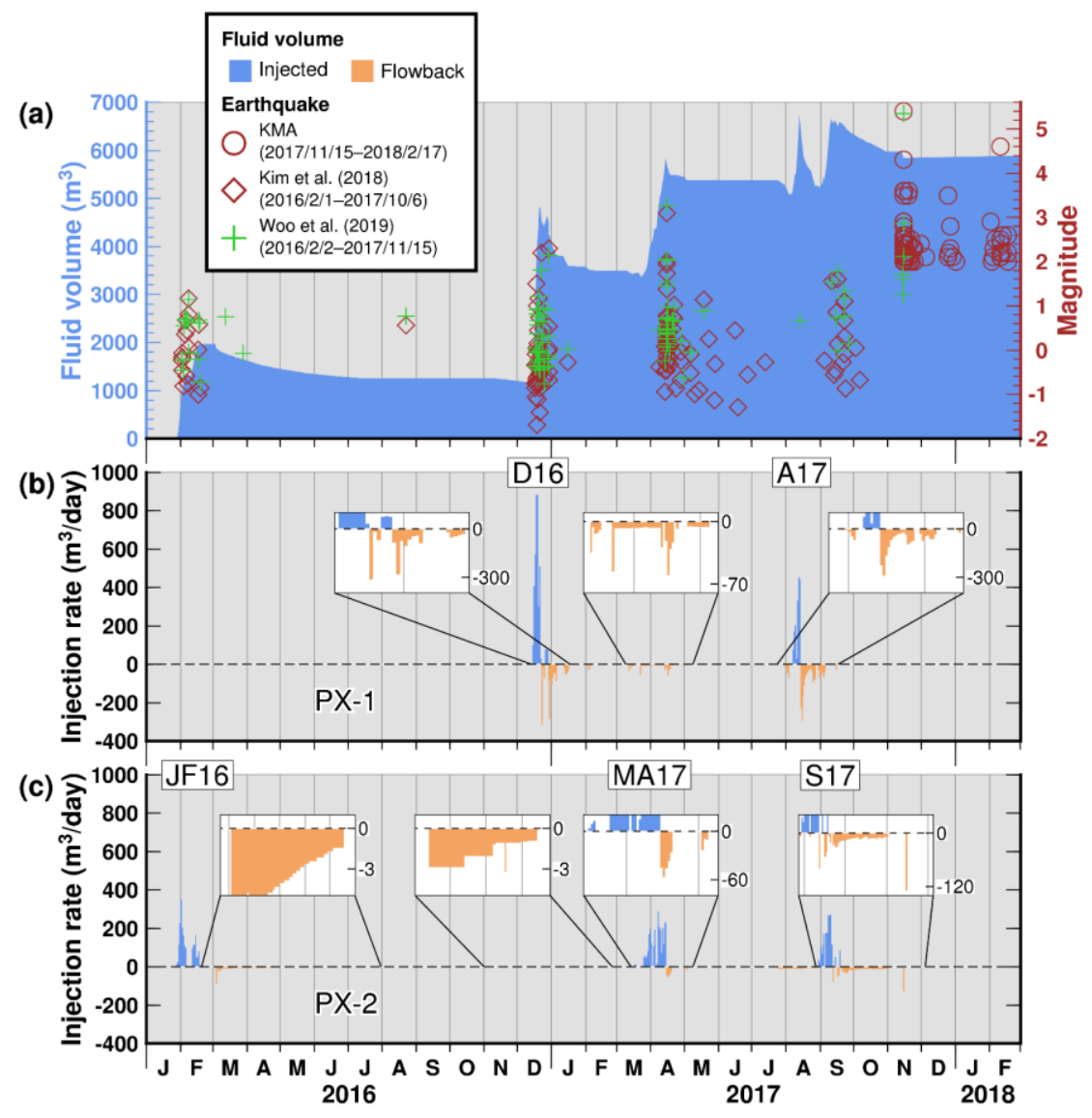

611 Figure 2. Fluid injection and flowback records for the Pohang enhanced geothermal system

612 (EGS) operation (Kim et al., 2018; KGC, 2019). The final fluid injection was performed in

613 September 2017 (Kim et al., 2018; KGC, 2019). (a) Cumulative net fluid volume and

614 earthquakes. Earthquakes reported by four sources (103 of them by the Korea Meteorological

615 Administration, 'http://necis.kma.go.kr/', last accessed on 26 February 2018; 135 by Kim et al.,

616 2018; and 97 by KGC, 2019 and Woo et al., 2019) are shown as circles, diamonds and crosses,

617 respectively. The catalogue of Kim et al. (2018) includes unlocatable earthquakes. Note that the

618 magnitude scales are different for the three catalogues. (b) Fluid injection and flowback rate at

619 the well PX-1. (c) Fluid injection and flowback rate at the well PX-2. Insets magnify the smaller 620 rates. Total injected volumes at PX-1 and PX-2 are 1,695 $\mathrm{m}^{3}$ and 4,146 $\mathrm{m}^{3}$, respectively. 
(a)

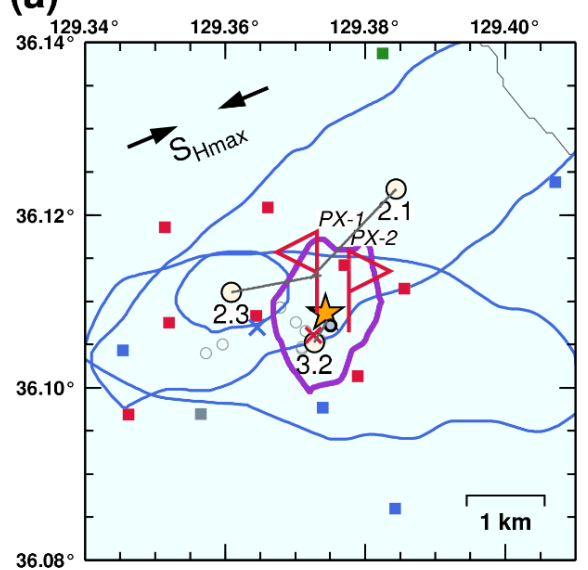

(c)

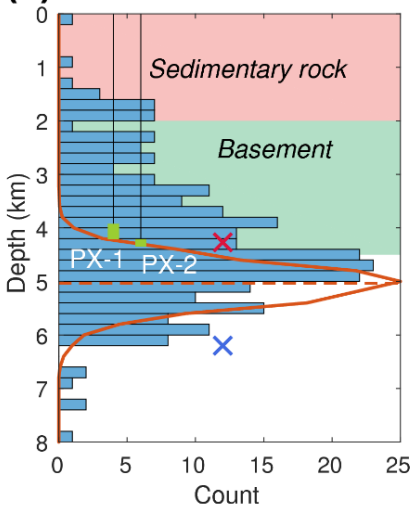

(b)
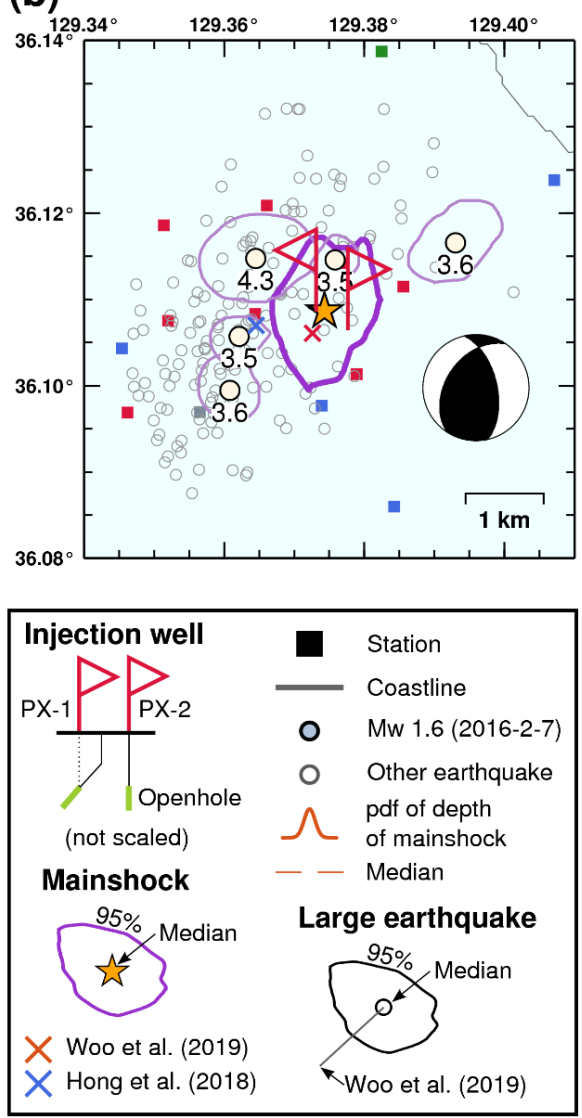

Figure 3. Earthquake epicenters in terms of probability density functions ( $p d f \mathrm{~s}$ ). (a) Epicentral $p d f$ s of the Pohang earthquake on 15 November 2017 05:29, Mw 1.6 earthquake on 7 February

624 2016, 22:04; Mw 2.1 earthquake on 22 December 2016, 20:31; Mw 2.3 earthquake on 29

625 December 2016, 12:32; and Mw 3.2 earthquake on 15 April 2017, 02:31 (Figure 2a). The

626 direction of the maximum horizontal principal stress $\left(\mathrm{S}_{\mathrm{Hmax}}\right)$ is indicated by black arrows (Soh et

627 al., 2018). The red and blue ' $\mathrm{X}$ ' symbols indicate the locations of the Pohang earthquake

628 according to Hong et al. (2018) and Woo et al. (2019), respectively. (b) Epicentral pdfs of the

629 Pohang earthquake and aftershocks. The information on the aftershocks, from top to bottom, is

630 as follows: 16 November 2017, 00:02 for $\mathrm{M}_{\mathrm{L}}$ 3.6; 15 November 2017, 07:49 for $\mathrm{M}_{\mathrm{L}} 4.3 ; 19$

631 November 2017, 14:45 for $\mathrm{M}_{\mathrm{L}}$ 3.5; 25 December 2017, 07:19 for $\mathrm{M}_{\mathrm{L}}$ 3.5; and 15 November

$6322017,05: 32$ for $M_{L}$ 3.6. An inset shows the focal mechanism used to obtain the $\triangle C F S$ in the 
633 poroelastic model $\left(214^{\circ}, 43^{\circ}\right.$ and $128^{\circ}$ for strike, dip and rake, respectively). (c) Focal depth $p d f$

634 of the Pohang earthquake and distribution of the earthquakes. Background colors represent

635 simplified geological strata information at a depth of 0-4.5 km (Lee et al., 2015). 

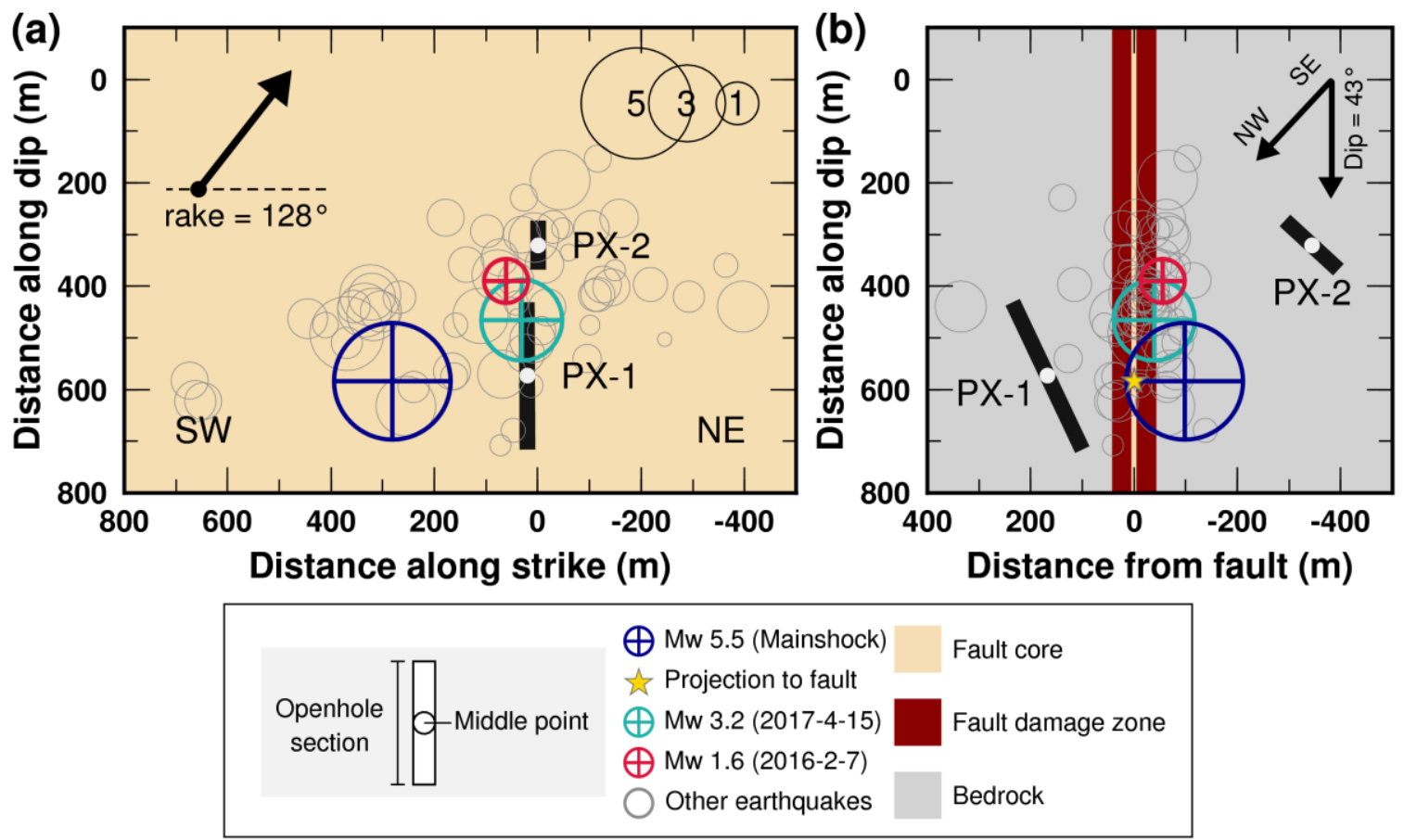

637 Figure 4. Geometry of the poroelastic modeling. (a) Fault-plane view. Openhole sections are represented as thick solid lines. In the model, the injection points for the wells PX-1 and PX-2 are at the mid-points of the openhole sections, marked as white circles. (b) Fault-normal view.

640 The fault-plane in (a) crosses the fault-core perpendicularly. The history of the poroelastic stress 641 is sampled at a projected point, marked as a yellow star, from the mainshock hypocenter. The 642 thicknesses of the fault core and damage zone are $10 \mathrm{~m}$ and $85 \mathrm{~m}$, respectively, following the 643 reported values (Ellsworth et al., 2019; KGC, 2019). The ranges of hydraulic diffusivity for the 644 damage zone and bedrock ( $D_{\mathrm{dmz}}$ and $D_{\text {bed, }}$, respectively) are searched independently. The strike $645\left(214^{\circ}\right), \operatorname{dip}\left(43^{\circ}\right)$, and rake $\left(128^{\circ}\right)$ of the fault, and the earthquake locations are from Woo et al. 646 (2019). Only the earthquakes associated with the injection at PX-2 are plotted (Woo et al., 2019).

647 The three largest earthquakes of the injection events JF16 (Mw 1.6), MA17 (Mw 3.2), and S17 648 (mainshock) are indicated as colored crossed circles. The origin points $(0 \mathrm{~m}, 0 \mathrm{~m})$ in (a) and (b) 649 are in PX-2, which is vertical, at a depth of $3.8 \mathrm{~km}$ (Woo et al., 2019). 
(a)

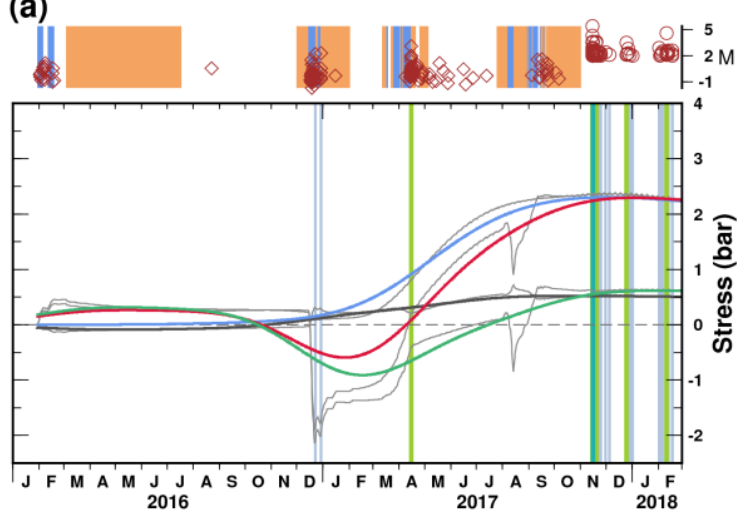

(b)

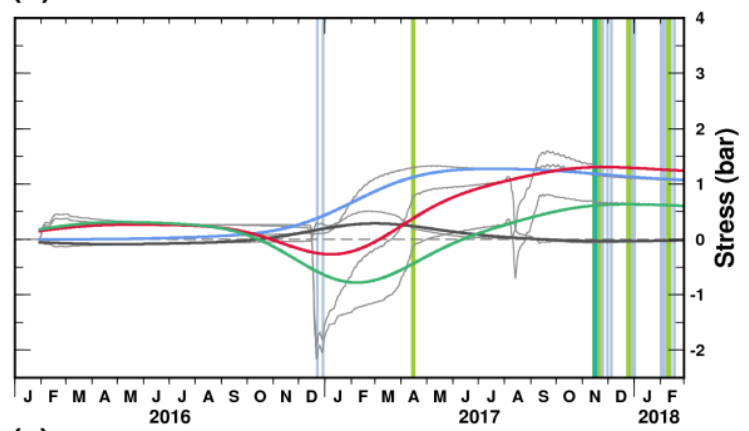

(c)

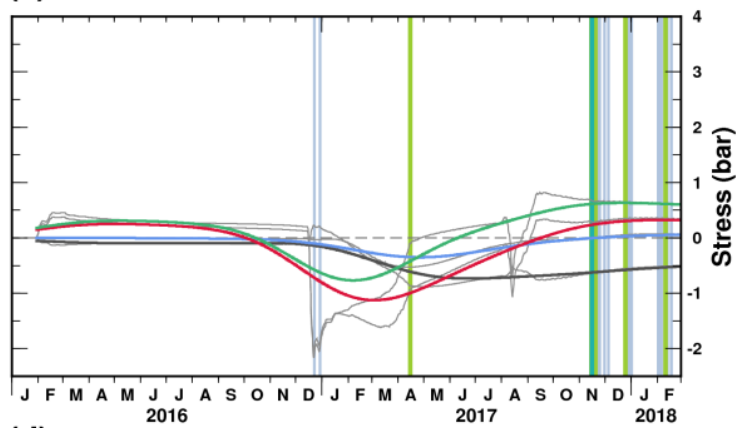

(d)

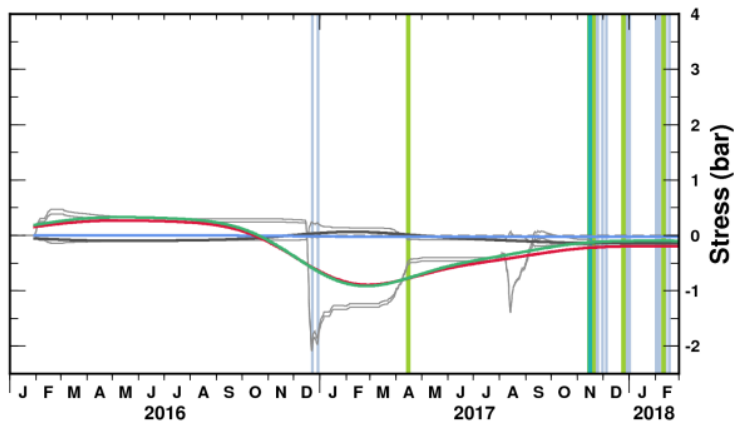

\begin{tabular}{|c|c|}
\hline \multirow{3}{*}{$\begin{array}{l}\text { Earthquake } \\
\qquad \begin{array}{l}\text { KMA } \\
(2017 / 11 / 15-2018 / 02 / 17)\end{array} \\
\diamond \begin{array}{l}\text { Kim et al. }(2018) \\
(2016 / 02 / 01-2017 / 10 / 06)\end{array}\end{array}$} & Injection \\
\hline & Flowback \\
\hline & Pohang earthquake \\
\hline $\begin{array}{ll}-\Delta C F S & =\Delta p \\
-\Delta \sigma_{\mathrm{n}} & =\Delta \tau\end{array}$ & $M \geq 3$ \\
\hline - Unfiltered - - Zero & $2 \leq M<3$ \\
\hline
\end{tabular}


651 Figure 5. Temporal changes in poroelastic stress changes between January 2016 and February

652 2018. The stresses are sampled where the mainshock hypocenter projects onto the fault plane

653 (yellow star in Figure 4b). (a) Homogeneous model. The hydraulic diffusivities for bedrock and

654 fault damage zone are: $D_{\text {bed }}=D_{\mathrm{dmz}}=5 \times 10^{-4} \mathrm{~m}^{2} / \mathrm{s}$. (b) Model including a permeable fault

655 damage zone. $D_{\text {bed }}=5 \times 10^{-4} \mathrm{~m}^{2} / \mathrm{s}$ and $D_{\mathrm{dmz}}=1 \times 10^{-2} \mathrm{~m}^{2} / \mathrm{s}$. (c) Model including a highly

656 permeable fault damage zone. $D_{\text {bed }}=5 \times 10^{-4} \mathrm{~m}^{2} / \mathrm{s}$ and $D_{\mathrm{dmz}}=1 \times 10^{1} \mathrm{~m}^{2} / \mathrm{s}$. (d) Model with

657 impermeable bedrock and a permeable fault damage zone. $D_{\text {bed }}=1 \times 10^{-6} \mathrm{~m}^{2} / \mathrm{s}$ and $D_{\mathrm{dmz}}=1 \times$

$65810^{-2} \mathrm{~m}^{2} / \mathrm{s}$. (Also, see Figure S3 for the result from the homogeneous model with

$659 D_{\mathrm{bed}}=D_{\mathrm{dmz}}=1 \times 10^{-2} \mathrm{~m}^{2} / \mathrm{s}$.) Gaussian lowpass filtered stresse changes (with a standard deviation

660 of 2 months) are shown as colored lines. Unfiltered stresse changes in background are shown as

661 grey lines. See Figure S4 for a version showing grey and color reversed. The filtered curves

662 show the Coulomb stress change ( $\triangle C F S$ ) tending to increase in (a), slightly increase in (b),

663 decrease in (c), and remain nearly constant in (d) around 15 November 2017. Upper panel shows

664 the history of the injection and flowback (Kim et al., 2018; KGC, 2019), and earthquakes (Kim

665 et al., 2018). $\Delta \tau$-Shear stress change. $\Delta p$-Pore pressure change. $\Delta \sigma_{\mathrm{n}}-$ Normal stress change.

666 M-Magnitude. 


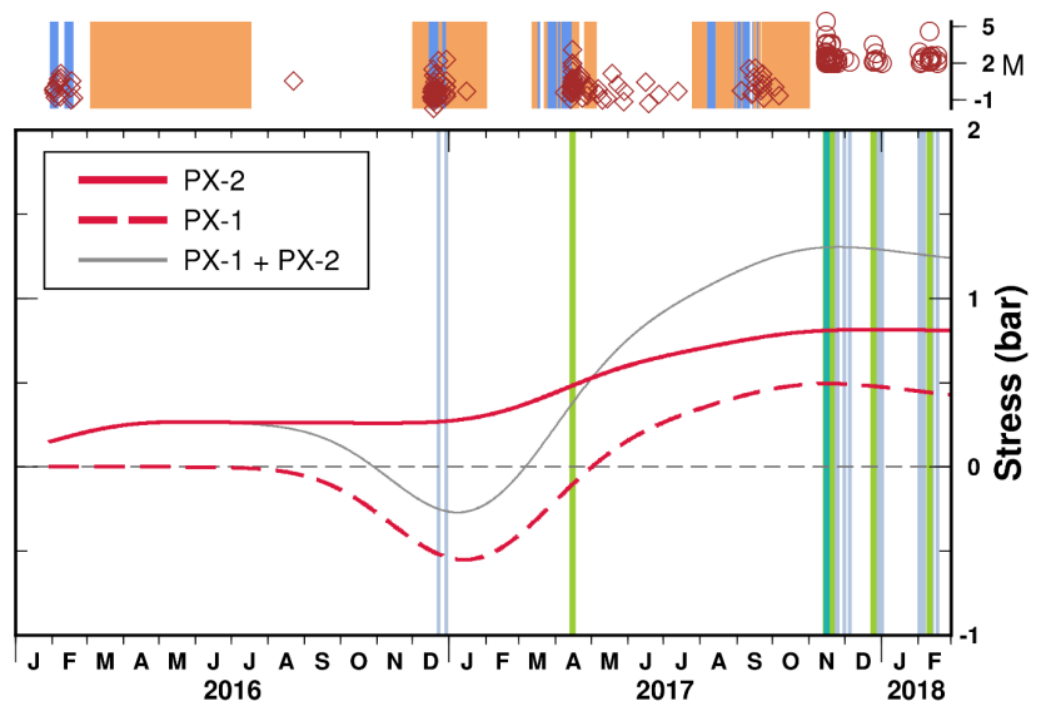

668 Figure 6. Coulomb failures stress change $(\triangle C F S)$ due to injection at each well. Hydraulic

669 diffusivities for bedrock and fault damage zone are set as $D_{\text {bed }}=5 \times 10^{-4} \mathrm{~m}^{2} / \mathrm{s}$ and $D_{\mathrm{dmz}}=1 \times 10^{-2}$

$670 \mathrm{~m} / 2 / \mathrm{s}$, respectively, which are the same as those for Figure $5 \mathrm{~b}$. The grey line is plotted as a

671 reference and represents $\triangle C F S$ considering both wells, also the same as in Figure $5 b$. See the

672 caption of Figure 5 for the definitions of the symbols and lines. 


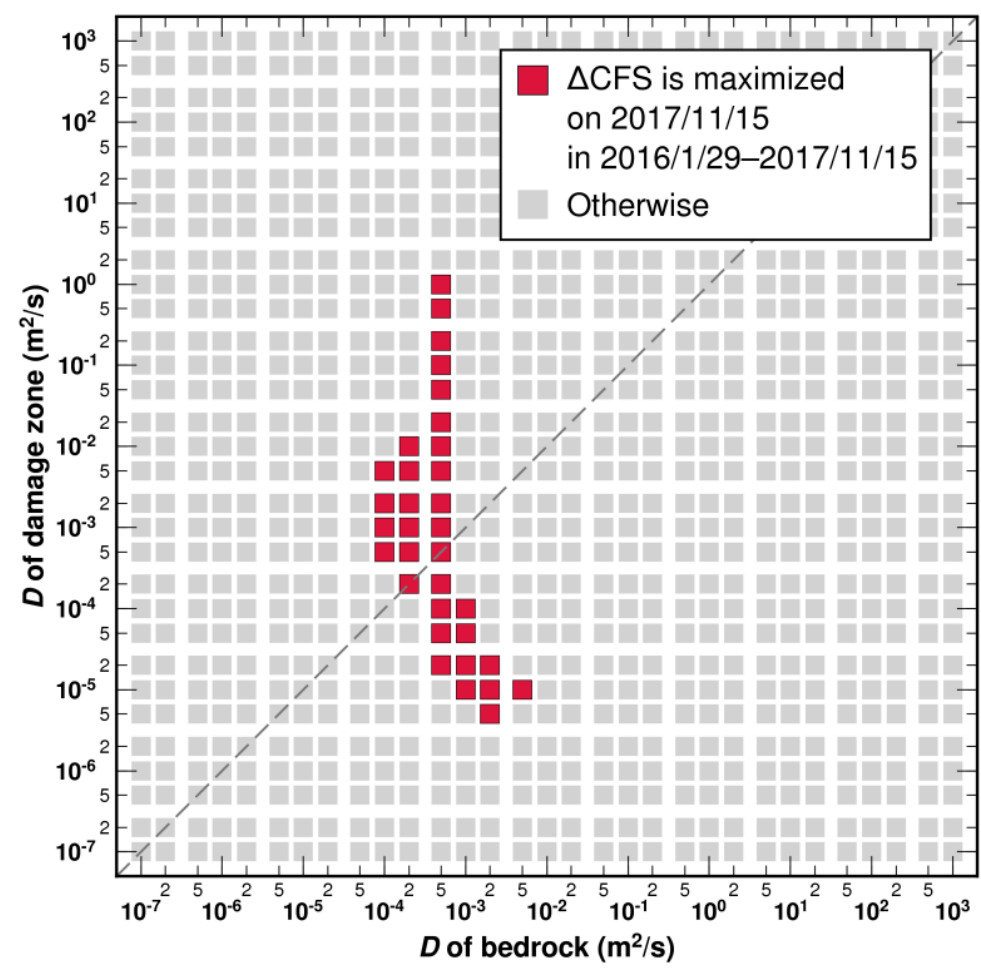

674 Figure 7. The ranges of hydraulic diffusivities for the fault damage zone and bedrock, $D_{\mathrm{dmz}}$ and

$675 D_{\text {bed }}$ respectively, that satisfy the criteria for the Coulomb stress change $(\triangle C F S)$ amplitude at the

676 time of the Pohang earthquake. A red square indicates values that meet the condition that $\triangle C F S$

677 is maximized on 15 November 2017, from within the period from 29 January 2016, until then.

678 Squares lying on the diagonal, dashed line indicate a homogeneous model (i.e., $D_{\text {core }}=D_{\text {dmz }}$ ). 
(a)

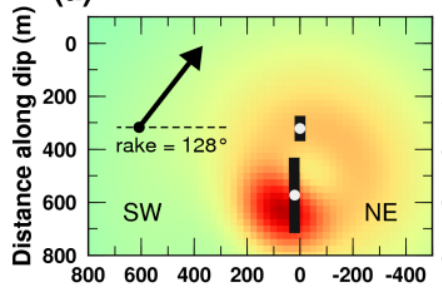

(e)

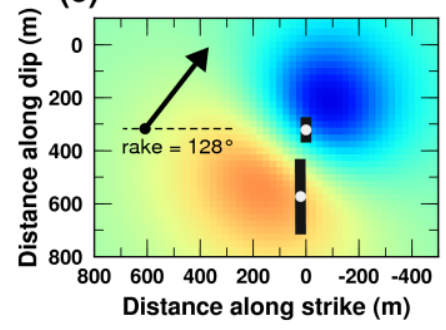

(f)

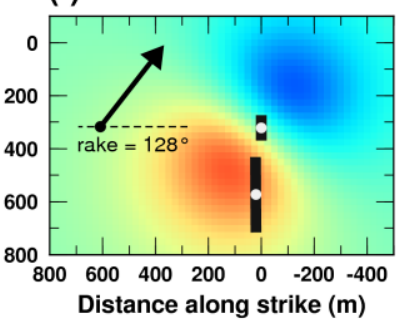

(g)

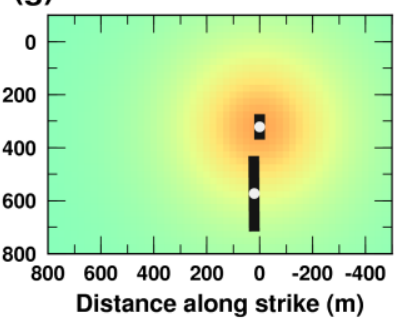

(c)
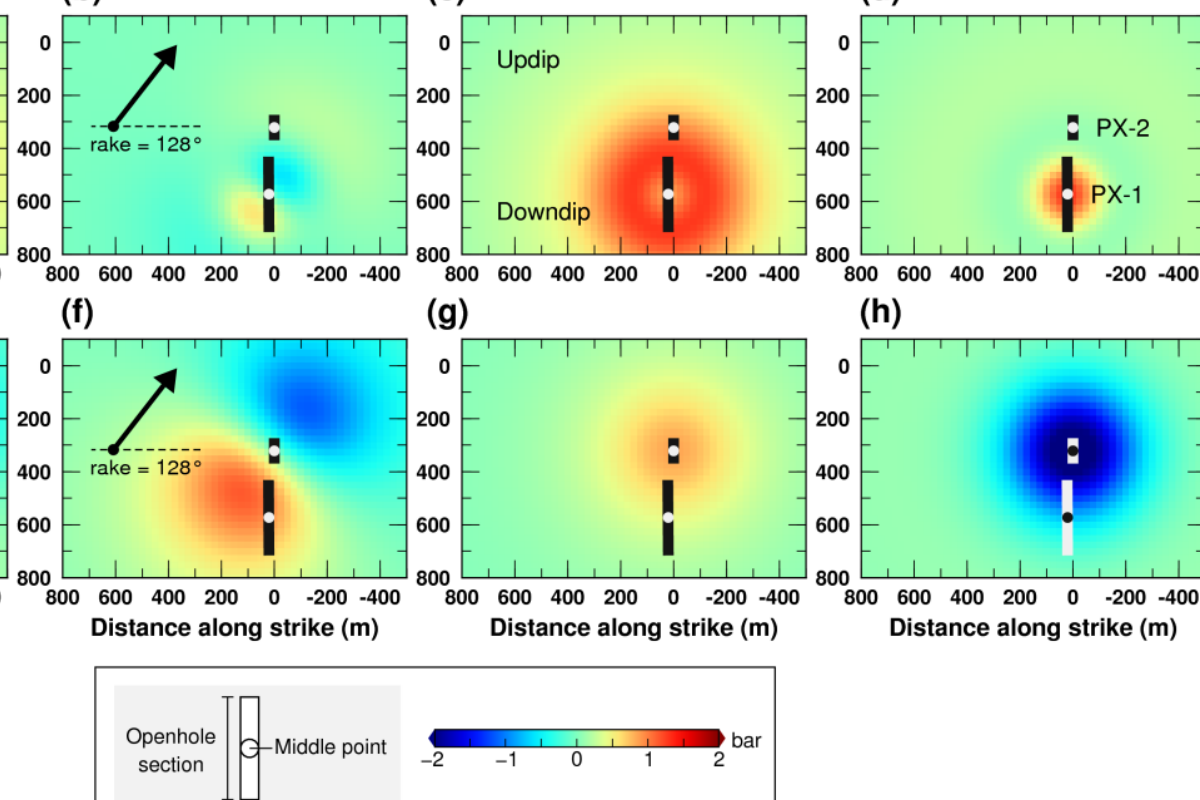

(d)

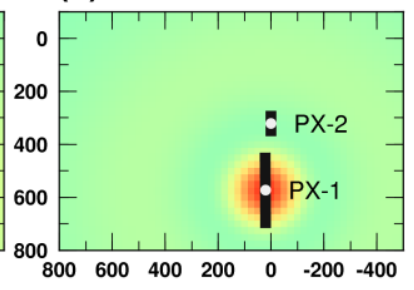

(h)

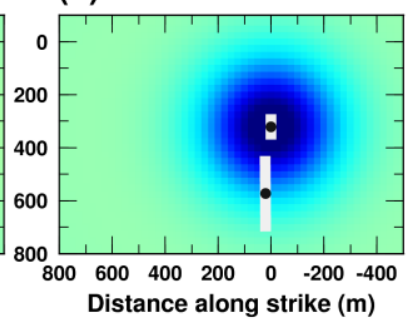

Figure 8. Snapshot images on 15 November 2017, for stresses and pore pressure changes due to injection at the wells $(\mathrm{a}-\mathrm{d}) \mathrm{PX}-1$ and $(\mathrm{e}-\mathrm{h}) \mathrm{PX}-2$. Hydraulic diffusivities for bedrock and fault damage zone are $D_{\text {bed }}=5 \times 10^{-4} \mathrm{~m}^{2} / \mathrm{s}$ and $D_{\mathrm{dmz}}=1 \times 10^{-2} \mathrm{~m}^{2} / \mathrm{s}$, respectively (same as Figure $5 \mathrm{~b}$ ). (a) Coulomb stress change $(\triangle C F S)$ by PX-1. (b) Shear stress change $(\Delta \tau)$ by PX-1. (c) Pore pressure change $(\Delta p)$ by PX-1. (d) Normal stress change $\left(\Delta \sigma_{\mathrm{n}}\right)$ by PX-1. (e) $\Delta C F S$ by PX-2. (f) $\Delta \tau$ by PX-2. (g) $\Delta p$ by PX-2. (h) $\Delta \sigma_{\mathrm{n}}$ by PX-2. $\Delta C F S$ is obtained by Equation (5) where $\mu=$ 

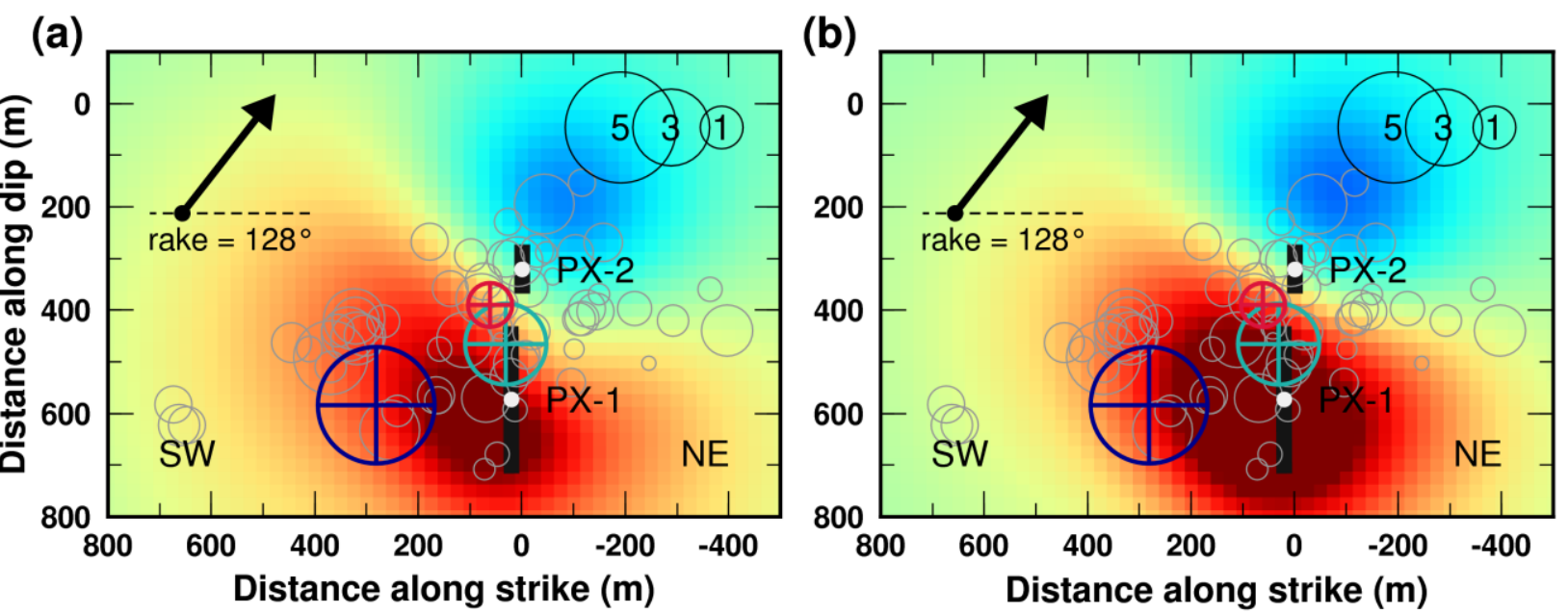

688 697 et al. (2019).

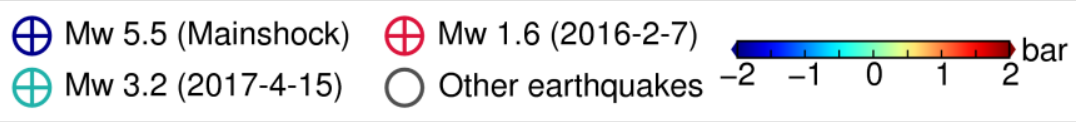

Figure 9. Total Coulomb stress $(\triangle C F S)$ on the fault plane caused by injection at the wells PX-1 and PX-2. This is the sum of the values of $\triangle C F S$ by PX-1 (Figure 8a) and PX-2 (Figure 8e). (a) $\triangle C F S$ without an impermeable core. (b) $\triangle C F S$ with the impermeable core. Thickness and hydraulic diffusivity, $D$, of the core are $10 \mathrm{~m}$ and $10^{-6} \mathrm{~m}^{2} / \mathrm{s}$, respectively, the same as those of Ellsworth et al. (2019) and KGC (2019; Figure 4b). See Figure S7 for pore pressure change, shear stress and normal stress changes by PX-1 and PX-2. Only the earthquakes associated with the injection at PX-2 are plotted (Woo et al., 2019). No temporal Gaussian filter is applied. Information of the fault geometry and earthquake locations are taken from KGC (2019) and Woo 


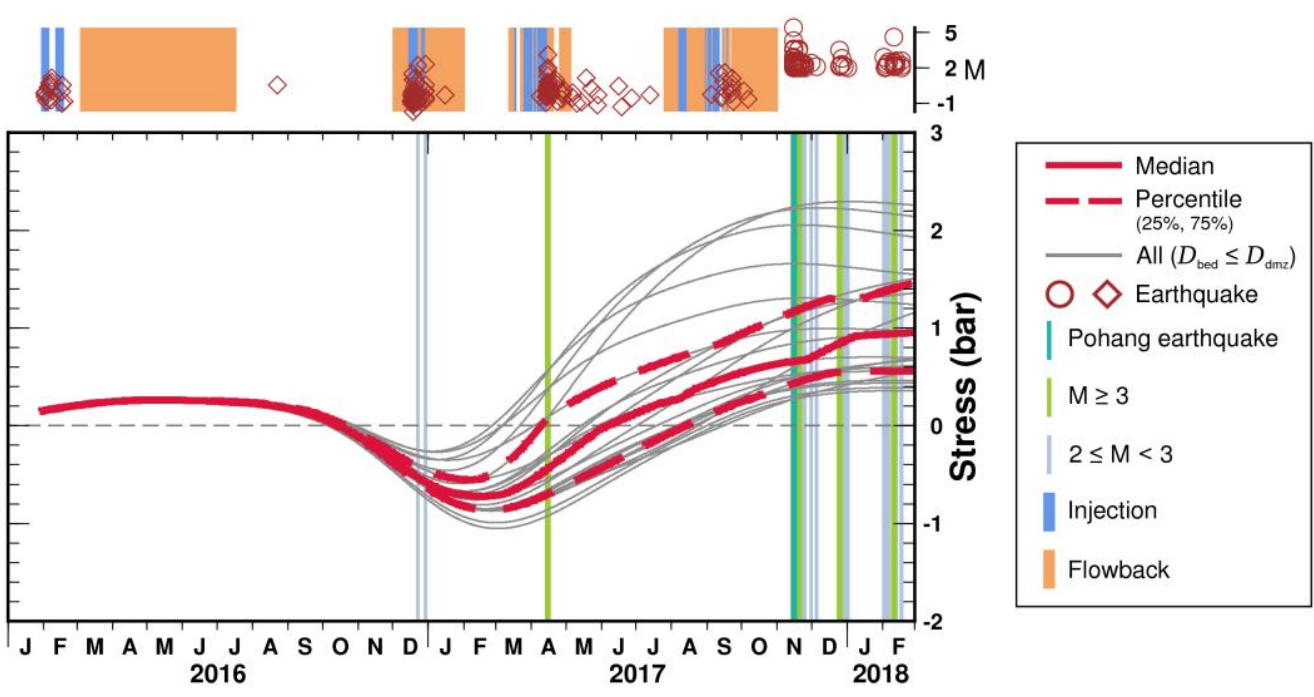

699 Figure 10. Temporal evolution in the Coulomb stress change $(\triangle C F S)$ satisfying the criterion for

700 its maximum amplitude on 15 November 2017, and also a condition that the hydraulic diffusivity

701 for the fault damage zone, $D_{\mathrm{dmz}}$, is larger than or equal to that for the bedrock, $D_{\text {bed }}$ (the 21 red

702 squares within the upper triangle in Figure 7). The median is indicated as a red solid line and the

703 25th and 75th percentiles as red dashed lines. Upper panel shows the history of the fluid injection

704 and flowback (Kim et al., 2018; KGC, 2019), and earthquakes (Kim et al., 2018). M-

705 Magnitude. 

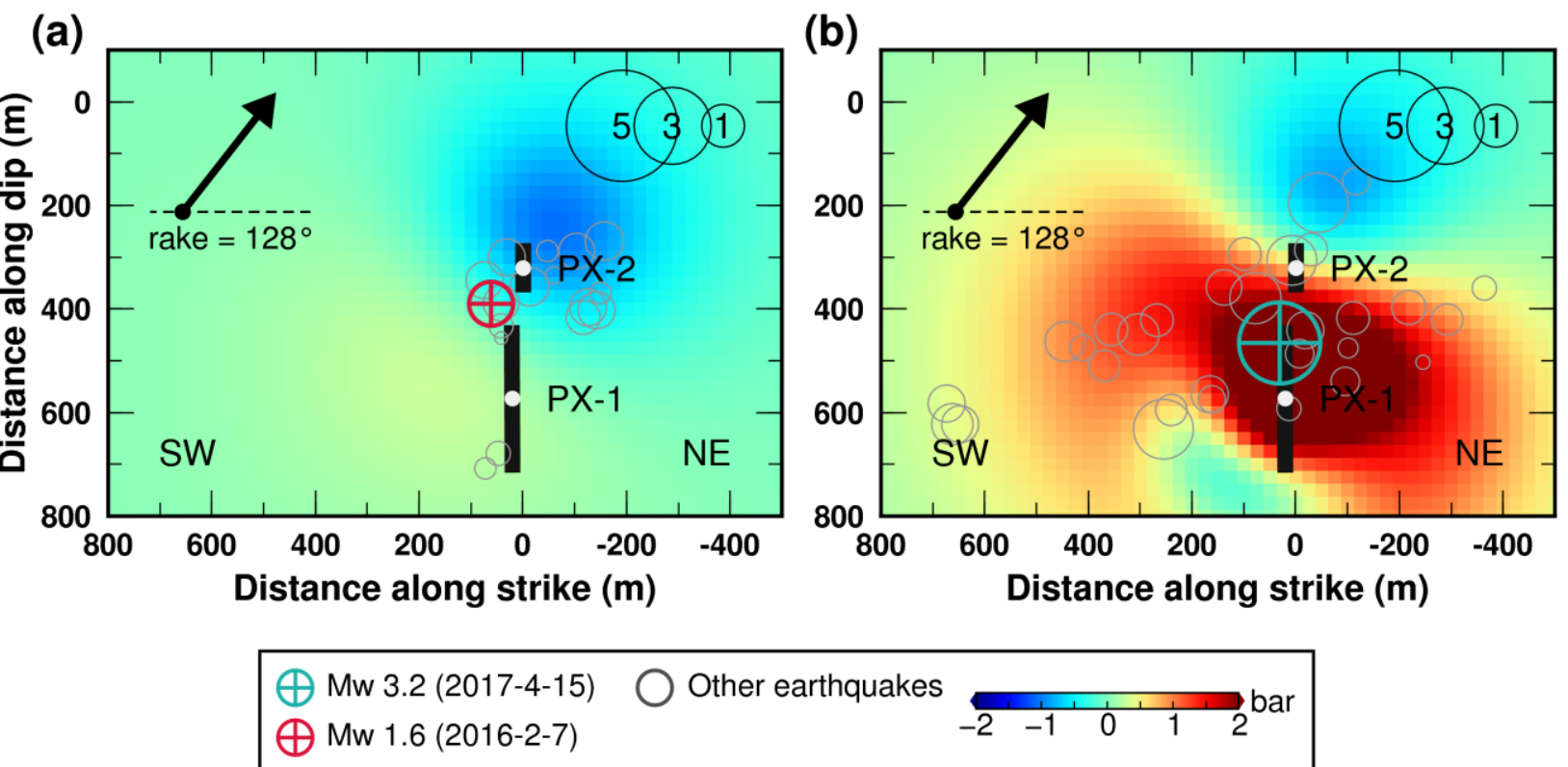

Figure 11. Coulomb stress change $(\triangle C F S)$ on the fault plane caused by injection at the wells

PX-1 and PX-2. The hydraulic diffusivities for bedrock and fault damage zone are $D_{\text {bed }}=5 \times 10^{-}$

${ }^{4} \mathrm{~m}^{2} / \mathrm{s}$ and $D_{\mathrm{dmz}}=1 \times 10^{-2} \mathrm{~m}^{2} / \mathrm{s}$, respectively (same as Figure $5 \mathrm{~b}$ ). (a) A snapshot of stress on

7 February 2016, when the Mw 1.6 earthquake, the largest event during the injection event JF16,

711 occurred. The other earthquakes before 22 August 2016 (KGC, 2019; Woo et al., 2019) are

712 shown as grey circles. (b) A snapshot of stress on 15 April 2017, when the Mw 3.2 earthquake,

713 the largest event during the injection event MA17, occurred. See Figure S8 for pore pressure,

714 shear stress and normal stress changes by PX-1 and PX-2. The other earthquakes from 8 April

7152017 to 18 May 2017 are shown as grey circles. No temporal Gaussian filter is applied. 


\section{Acknowledgments}

717

718

719

720

721

722

723

724 article.

H. Lim and Y. Kim would like to acknowledge the Creative-Pioneering Researchers Program of Seoul National University (SNU SRnD 3345-20160014). H. Lim, Y. Kim, J.-H. Ree, and K.-H. Kim acknowledge the Nuclear Safety Research Program of the Korea Foundation of Nuclear Safety (KoFONS) that were granted financial resources by the Nuclear Safety and Security Commission (NSSC), Republic of Korea (No. 1705010). T.-R A. Song acknowledges the support by the Natural Environment Research Council, UK (NE/P001378/1). The software for linear poroelasticity calculation is from 'https://www.gfz-potsdam.de/en/section/physics-ofearthquakes-and-volcanoes/data-products-services/downloads-software/' (Wang and Kümpel, 2003; last accessed on 21 June 2017). The authors would like to thank the universities and research institutes that supplied the seismic data used in this study: the Korea Institute of Geoscience and Mineral Resources, Korea Meteorological Administration (KMA), Korea Hydro \& Nuclear Power Co., Ltd., Seoul National University (SNU), Pukyong National University, and Pusan National University. The waveform data and earthquake catalogue from the KMA are accessible online at 'http://necis.kma.go.kr' (last accessed on 9 April and 2 May 2018, respectively). The authors are grateful for the help of E. Kim (SNU) and J. Kim (SNU) in determining the arrival times of the aftershocks. Finally, the authors thank Editor Y. Ben-Zion, Associate Editor, A. McGarr and the reviewers for their comments, which greatly improved this 


\section{References}

Biot, M. A. (1941). General Theory of Three-Dimensional Consolidation. Journal of Applied Physics, 12(2), 155-164. https://doi.org/10.1063/1.1712886

Byerlee, J. (1978). Friction of rocks. Pure and Applied Geophysics PAGEOPH, 116(4-5), 615626. https://doi.org/10.1007/BF00876528

Chang, K. W., Yoon, H., Kim, Y., \& Lee, M. Y. (2020). Operational and geological controls of coupled poroelastic stressing and pore-pressure accumulation along faults: Induced earthquakes in Pohang, South Korea. Scientific Reports, 10(1), 2073. https://doi.org/10.1038/s41598-020-58881-z

Coyner, K. B. (1984). Effects of stress, pore pressure, and pore fluids on bulk strain, velocity, and permeability in rocks. Massachusetts Institute of Technology. Retrieved from http://hdl.handle.net/1721.1/15367

Deng, K., Liu, Y., \& Harrington, R. M. (2016). Poroelastic stress triggering of the December 2013 Crooked Lake, Alberta, induced seismicity sequence. Geophysical Research Letters, 43(16), 8482-8491. https://doi.org/10.1002/2016GL070421

Detournay, E., \& Cheng, A. H. D. (1993), Fundamentals of poroelasticity, book section 5, in Comprehensive Rock Engineering, vol. 2, edited by J. A. Hudson, pp. 113-171, Pergamon Press, Oxford, U. K. 
Dieterich, J. (1994). A constitutive law for rate of earthquake production and its application to earthquake clustering. Journal of Geophysical Research: Solid Earth, 99(B2), 2601-2618. https://doi.org/10.1029/93JB02581

Doglioni, C. (2018). A classification of induced seismicity. Geoscience Frontiers, 9(6), 19031909. https://doi.org/10.1016/j.gsf.2017.11.015

Ellsworth, W. L., \& Beroza, G. C. (1995). Seismic Evidence for an Earthquake Nucleation Phase. Science, 268(5212), 851-855. https://doi.org/10.1126/science.268.5212.851

Ellsworth, W. L. (2013). Injection-Induced Earthquakes. Science, 341(6142), 1225942-1225942. https://doi.org/10.1126/science.1225942

Ellsworth, W. L., Giardini, D., Townend, J., Ge, S., \& Shimamoto, T. (2019). Triggering of the Pohang, Korea, Earthquake (Mw 5.5) by Enhanced Geothermal System Stimulation. Seismological Research Letters. https://doi.org/10.1785/0220190102

Foulger, G. R., Wilson, M. P., Gluyas, J. G., Julian, B. R., \& Davies, R. J. (2018). Global review of human-induced earthquakes. Earth-Science Reviews, 178, 438-514. https://doi.org/10.1016/j.earscirev.2017.07.008

Galis, M., Ampuero, J. P., Mai, P. M., \& Cappa, F. (2017). Induced seismicity provides insight into why earthquake ruptures stop. Science Advances, 3(12). https://doi.org/10.1126/sciadv.aap7528

Grigoli, F., Cesca, S., Rinaldi, A. P., Manconi, A., López-Comino, J. A., Clinton, J. F., et al. (2018). The November $2017 \mathrm{M}_{\mathrm{w}} 5.5$ Pohang earthquake: A possible case of induced 
seismicity in South Korea. Science, 360(6392), 1003-1006.

https://doi.org/10.1126/science.aat2010

Gupta, H. K. (2002). A review of recent studies of triggered earthquakes by artificial water reservoirs with special emphasis on earthquakes in Koyna, India. Earth-Science Reviews, 58(3-4), 279-310. https://doi.org/10.1016/S0012-8252(02)00063-6

Hart, D. J., \& Wang, H. F. (1995). Laboratory measurements of a complete set of poroelastic moduli for Berea sandstone and Indiana limestone. Journal of Geophysical Research: Solid Earth, 100(B9), 17741-17751. https://doi.org/10.1029/95JB01242

Hincks, T., Aspinall, W., Cooke, R., \& Gernon, T. (2018). Oklahoma’s induced seismicity strongly linked to wastewater injection depth. Science, 359(6381), 1251-1255. https://doi.org/10.1126/science.aap7911

Hofmann, H., Zimmermann, G., Farkas, M., Huenges, E., Zang, A., Leonhardt, M., et al. (2019). First field application of cyclic soft stimulation at the Pohang Enhanced Geothermal System site in Korea. Geophysical Journal International. https://doi.org/10.1093/gji/ggz058

Hong, T.-K., Lee, J., Park, S., \& Kim, W. (2018). Time-advanced occurrence of moderate-size earthquakes in a stable intraplate region after a megathrust earthquake and their seismic properties. Scientific Reports, 8(1), 13331. https://doi.org/10.1038/s41598-018-31600-5

Hughes, D. S., \& Jones, H. J. (1950). Variation of elastic moduli of igneous rocks with pressure and temperature. Bulletin of the Geological Society of America, 61(8), 843-856. https://doi.org/10.1130/0016-7606(1950)61[843:VOEMOI]2.0.CO;2 
Johnson, C. W., Fu, Y., \& Bürgmann, R. (2017). Stress Models of the Annual Hydrospheric, Atmospheric, Thermal, and Tidal Loading Cycles on California Faults: Perturbation of Background Stress and Changes in Seismicity. Journal of Geophysical Research: Solid Earth, 122(12), 10,605-10,625. https://doi.org/10.1002/2017JB014778

Kim, H. C., \& Lee, Y. (2007). Heat flow in the Republic of Korea. Journal of Geophysical Research, 112(B5), B05413. https://doi.org/10.1029/2006JB004266

Kim, K.-H., Ree, J.-H., Kim, Y., Kim, S., Kang, S. Y., \& Seo, W. (2018). Assessing whether the 2017 Mw 5.4 Pohang earthquake in South Korea was an induced event. Science, 360(6392), 1007-1009. https://doi.org/10.1126/science.aat6081

Kim, S., Rhie, J., \& Kim, G. (2011). Forward waveform modelling procedure for 1-D crustal velocity structure and its application to the southern Korean Peninsula. Geophysical Journal International, 185(1), 453-468. https://doi.org/10.1111/j.1365-246X.2011.04949.x

Kim, Y., He, X., Ni, S., Lim, H., \& Park, S. (2017). Earthquake Source Mechanism and Rupture Directivity of the 12 September 2016 Mw 5.5 Gyeongju, South Korea, Earthquake. Bulletin of the Seismological Society of America, 107(5), 2525-2531. https://doi.org/10.1785/0120170004

King, Geoffrey C. P. and Stein, Ross S. and Lin, J. (1994). Static stress changes and the triggering of earthquakes. Bulletin of the Seismological Society of America, 84(3), 935-953.

Korean Government Commission (2019). Final report of the Korean Government Commission on relations between the 2017 Pohang earthquake and EGS Project. Seoul, South Korea. https://doi.org/10.22719/KETEP-2019043001 
813 Kwon, S., Xie, L., Park, S., Kim, K.-I., Min, K.-B., Kim, K. Y., et al. (2018). Characterization of 4.2-km-Deep Fractured Granodiorite Cores from Pohang Geothermal Reservoir, Korea. Rock Mechanics and Rock Engineering, 52(3), 771-782. https://doi.org/10.1007/s00603-018-1639-

Lee, K., Chung, N. S., \& Chung, T. W. (2003). Earthquakes in Korea from 1905 to 1945. Bulletin of the Seismological Society of America, 93(5), 2131-2145. https://doi.org/10.1785/0120020176

820

Lee, T. J., Song, Y., Park, D.-W., Jeon, J., \& Yoon, W. S. (2015). Three Dimensional Geological Model of Pohang EGS Pilot Site, Korea. Paper presented at World Geothermal Congress, Melbourne, Australia.

Lee, T. J., Song, Y. H., \& Uchida, T. (2005). Two-Dimensional Interpretation of Far-Remote Reference Magnetotelluric Data for Geothermal Application (in Korean). Mulli-Tamsa, 8, 145-155.

Lee, Y., Park, S., Kim, J., Kim, H. C., \& Koo, M.-H. (2010). Geothermal Resource Assessment for EGS in Korea. Paper presented at Proceedings World Geothermal Congress. Bali, Indonesia.

Marone, C., \& Scholz, C. H. (1988). The depth of seismic faulting and the upper transition from stable to unstable slip regimes. Geophysical Research Letters, 15(6), 621-624. https://doi.org/10.1029/GL015i006p00621

McGarr, A. (2014). Maximum magnitude earthquakes induced by fluid injection. Journal of Geophysical Research: Solid Earth, 119(2), 1008-1019. 
Mizoguchi, K., Hirose, T., Shimamoto, T., \& Fukuyama, E. (2008). Internal structure and permeability of the Nojima fault, southwest Japan. Journal of Structural Geology, 30(4), 513524. https://doi.org/10.1016/j.jsg.2007.12.002

Morrow, C., Lockner, D., Hickman, S., Rusanov, M., \& Röckel, T. (1994). Effects of lithology and depth on the permeability of core samples from the Kola and KTB drill holes. Journal of Geophysical Research, 99(B4), 7263. https://doi.org/10.1029/93JB03458

Myers, S. C., Johannesson, G., \& Hanley, W. (2007). A Bayesian hierarchical method for multiple-event seismic location. Geophysical Journal International, 171(3), 1049-1063. https://doi.org/10.1111/j.1365-246X.2007.03555.x

Ohnaka, M. (1993). Critical Size of the Nucleation Zone of Earthquake Rupture Inferred from Immediate Foreshock Activity. Journal of Physics of the Earth, 41(1), 45-56. https://doi.org/10.4294/jpe1952.41.45

Park, S., Xie, L., Kim, K.-I., Kwon, S., Min, K.-B., Choi, J., et al. (2017). First Hydraulic Stimulation in Fractured Geothermal Reservoir in Pohang PX-2 Well. Procedia Engineering, 191, 829-837. https://doi.org/10.1016/j.proeng.2017.05.250

Reasenberg, P. A., \& Simpson, R. W. (1992). Response of Regional Seismicity to the Static Stress Change Produced by the Loma Prieta Earthquake. Science, 255(5052), 1687-1690. https://doi.org/10.1126/science.255.5052.1687

Rice, J. R., \& Cleary, M. P. (1976). Some basic stress diffusion solutions for fluid-saturated 
elastic porous media with compressible constituents. Reviews of Geophysics, 14(2), 227. https://doi.org/10.1029/RG014i002p00227

Shapiro, S. A., Huenges, E., \& Borm, G. (1997). Estimating the crust permeability from fluidinjection-induced seismic emission at the KTB site. Geophysical Journal International, 131(2), F15-F18. https://doi.org/10.1111/j.1365-246X.1997.tb01215.X

Scholz, C. H. (1998). Earthquakes and friction laws. Nature, 391(6662), 37-42. https://doi.org/10.1038/34097

Segall, P., \& Lu, S. (2015). Injection-induced seismicity: Poroelastic and earthquake nucleation effects. Journal of Geophysical Research: Solid Earth, 120(7), 5082-5103. https://doi.org/10.1002/2015JB012060

Soh, I., Chang, C., Lee, J., Hong, T.-K., \& Park, E.-S. (2018). Tectonic stress orientations and magnitudes, and friction of faults, deduced from earthquake focal mechanism inversions over the Korean Peninsula. Geophysical Journal International, 213(2), 1360-1373. https://doi.org/10.1093/gji/ggy061

Song, S. G., \& Lee, H. (2019). Static Slip Model of the 2017 Mw 5.4 Pohang, South Korea, Earthquake Constrained by the InSAR Data. Seismological Research Letters. https://doi.org/10.1785/0220180156

Stein, R. S. (1999). The role of stress transfer in earthquake occurrence. Nature, 402(6762), 605609. https://doi.org/10.1038/45144

Wang, R., \& Kümpel, H. (2003). Poroelasticity: Efficient modeling of strongly coupled, slow 
874 deformation processes in a multilayered half-space. GEOPHYSICS, 68(2), 705-717.

875 https://doi.org/10.1190/1.1567241

876 Woessner, J., Jónsson, S., Sudhaus, H., \& Baumann, C. (2012). Reliability of Coulomb stress

877 changes inferred from correlated uncertainties of finite-fault source models. Journal of

878 Geophysical Research: Solid Earth, 117(7), 1-14. https://doi.org/10.1029/2011JB009121

879 Wonham, J. (1967). Effect of Pressure on the Viscosity of Water. Nature, 215(5105), 1053-

$880 \quad$ 1054. https://doi.org/10.1038/2151053a0

881 Woo, J. -U., Kim, M., Sheen, D. -H., Kang, T. -S., Rhie, J., Grigoli, F., et al. (2019). An In-

882 Depth Seismological Analysis Revealing a Causal Link Between the 2017 MW 5.5 Pohang

883 Earthquake and EGS Project. Journal of Geophysical Research: Solid Earth,

884 2019JB018368. https://doi.org/10.1029/2019JB018368

885 Yoo, H. (2018). Numerical modeling of hydraulic stimulation at a fractured geothermal

886 reservoir. Retrieved from 'http://s-

887 space.snu.ac.kr/bitstream/10371/141462/1/000000150962.pdf’. Location: Seoul National

888 University. 